\title{
Synaptic Specificity and Application of Anterograde Transsynaptic AAV for Probing Neural Circuitry
}

\author{
Brian Zingg, ${ }^{1,3}$ Bo Peng, ${ }^{1,3}$ Junxiang Huang, ${ }^{1,3}$ Huizhong W. Tao, ${ }^{1,2}$ and Li I. Zhang ${ }^{1,2}$ \\ ${ }^{1}$ Zilkha Neurogenetic Institute, ${ }^{2}$ Department of Physiology and Neuroscience, and ${ }^{3}$ Neuroscience Graduate Program, Keck School of Medicine, \\ University of Southern California, Los Angeles, California 90033
}

Revealing the organization and function of neural circuits is greatly facilitated by viral tools that spread transsynaptically. Adeno-associated virus (AAV) exhibits anterograde transneuronal transport, however, the synaptic specificity of this spread and its broad application within a diverse set of circuits remains to be explored. Here, using anatomic, functional, and molecular approaches, we provide evidence for the preferential transport of AAV1 to postsynaptically connected neurons and reveal its spread is strongly dependent on synaptic transmitter release. In addition to glutamatergic pathways, AAV1 also spreads through GABAergic synapses to both excitatory and inhibitory cell types. We observed little or no transport, however, through neuromodulatory projections (e.g., serotonergic, cholinergic, and noradrenergic). In addition, we found that AAV1 can be transported through long-distance descending projections from various brain regions to effectively transduce spinal cord neurons. Combined with newly designed intersectional and sparse labeling strategies, AAV1 can be applied within a wide variety of pathways to categorize neurons according to their input sources, morphology, and molecular identities. These properties make AAV1 a promising anterograde transsynaptic tool for establishing a comprehensive cell-atlas of the brain, although its capacity for retrograde transport currently limits its use to unidirectional circuits.

\section{Significance Statement}

The discovery of anterograde transneuronal spread of AAV1 generates great promise for its application as a unique tool for manipulating input-defined cell populations and mapping their outputs. However, several outstanding questions remain for anterograde transsynaptic approaches in the field: (1) whether AAV1 spreads exclusively or specifically to synaptically connected neurons, and (2) how broad its application could be in various types of neural circuits in the brain. This study provides several lines of evidence in terms of anatomy, functional innervation, and underlying mechanisms, to strongly support that AAV1 anterograde transneuronal spread is highly synapse specific. In addition, several potentially important applications of transsynaptic AAV1 in probing neural circuits are described.

\section{Introduction}

Viral tools that spread transsynaptically provide a powerful means for establishing the organization and function of neural circuits (Wickersham et al., 2007; Gradinaru et al., 2010; Beier et al., 2011; Beier, 2019; Lo and Anderson, 2011; Nassi et al., 2015; Zeng et al., 2017; Luo et al., 2018). Adeno-associated virus (AAV) has recently been shown to be capable of anterograde transneuronal transport (Castle et al., 2014a,b; Hutson et al., 2016; Zingg et al., 2017), with serotype 1 (AAV1) in particular

\footnotetext{
Received Sep. 6, 2019; revised Mar. 5, 2020; accepted Mar. 8, 2020

Author contributions: H.W.T. and L.I.Z. designed research; B.Z., B.P., and J.H. performed research; B.Z., B. P., and J.H. analyzed data; B.Z., H.W.T., and L.I.Z. wrote the paper.

This work was supported by Grants from the U.S. National Institutes of Health to L.I.Z. (R01DC008983; RF1MH114112; U01MH116990), and H.W.T. (EY019049; EY022478).

Correspondence should be addressed to Li I. Zhang at liizhang@usc.edu or Huizhong W. Tao at htao@usc. edu.

https://doi.org/10.1523/JNEUROSCI.2158-19.2020

Copyright $\odot 2020$ the authors
}

exhibiting the greatest efficiency of spread (Zingg et al., 2017). Given its well established lack of toxicity and apparent transduction of only first-order postsynaptic neurons, AAV1 shows great promise as a tool for manipulating input-defined cell populations and mapping their outputs. This approach has become more widely used recently (Cembrowski et al., 2018; Wang et al., 2018; Yao et al., 2018; Beltramo and Scanziani, 2019; Bennett et al., 2019; Centanni et al., 2019; Huang et al., 2019; Sengupta and Holmes, 2019; Trouche et al., 2019), however, care must be taken to apply it only in unidirectional circuits, given that AAV1 also exhibits retrograde transport capabilities (Rothermel et al., 2013; Zingg et al., 2017).

Previous work suggests that AAV1 is released at or near axon terminals, and transduced neurons downstream of the injection site show a high probability of receiving functional synaptic input in slice recording experiments (Zingg et al., 2017). However, the extent to which AAV1 spreads exclusively to synaptically connected neurons remains uncertain. In addition, 
despite clear evidence for the active trafficking of AAV-containing vesicles down the axon (Castle et al., 2014a,b), exactly how AAV is eventually released (e.g., through synaptic or extrasynaptic vesicle fusion) remains unknown. Addressing these questions will be essential for establishing the synaptic nature of AAV transneuronal transduction.

AAV1 has been shown to efficiently transduce both excitatory and inhibitory neurons downstream of a variety of glutamatergic corticofugal pathways (Zingg et al., 2017; Wang et al., 2018; Yao et al., 2018; Bennett et al., 2019; Centanni et al., 2019). In addition, this efficiency appears to be critically dependent on viral titer, as reducing the titer from 1013 to $1011 \mathrm{GC} / \mathrm{ml}$ completely eliminates transneuronal spread (Zingg et al., 2017). Given the molecular diversity among different cell types in the brain, it remains uncertain whether differences in cell surface receptor expression, intracellular trafficking, or synapse type might limit the efficiency of AAV spread in certain pathways. In particular, transneuronal spread through inhibitory projection neurons or neuromodulatory cell populations has yet to be directly examined. Moreover, whether or not axon length might diminish spread (e.g., from cortex to spinal cord) remains to be tested.

In this study, we systematically examine the synaptic specificity of AAV1 transneuronal transport using a variety of anatomic, functional, and molecular approaches. We find a strong correspondence between presynaptic connectivity and postsynaptic labeling for different pathways, and find that coexpression of tetanus toxin light chain, an inhibitor of presynaptic vesicle fusion, nearly abolishes transsynaptic spread of AAV. In addition, we establish that AAV1 spreads efficiently through inhibitory projection pathways, as well as long-range pathways from the brain to the spinal cord, but shows little or no spread through all neuromodulatory projections examined. Last, we expand the application potential for this technique by combining Flp- and Cre-dependent mapping in dual-reporter mice and incorporate its use with approaches for the sparse labeling of input- and genetically-defined neurons.

\section{Materials and Methods}

\section{Animal preparation and stereotaxic surgery}

All experimental procedures used in this study were approved by the Animal Care and Use Committee at the University of Southern California. Male and female Ai14 (Cre-dependent tdTomato reporter; Jackson Laboratories, stock \#007914) and Frt-GFP (Flp-dependent GFP reporter; MMRRC, stock \#32 038) mice aged 2-6 months were used in this study. Mice were group housed in a light controlled $(12 \mathrm{~h} \mathrm{light/dark}$ cycle) environment with ad libitum access to food and water.

Stereotaxic injection of viruses was conducted as we previously described (Zingg et al., 2017; Ibrahim et al., 2016; Liang et al., 2015; Xiong et al., 2015). Mice were anesthetized initially in an induction chamber containing $5 \%$ isoflurane mixed with oxygen and then transferred to a stereotaxic frame equipped with a heating pad. Anesthesia was maintained throughout the procedure using continuous delivery of $2 \%$ isoflurane through a nose cone at a rate of $1.5 \mathrm{~L} / \mathrm{min}$. The scalp was shaved and a small incision was made along the midline to expose the skull. After leveling the head relative to the stereotaxic frame, injection coordinates based on the Allen Reference Atlas (Dong, 2007) were used to mark the location on the skull directly above the target area and a small hole $(0.5 \mathrm{~mm}$ diameter $)$ was drilled. Viruses were delivered through pulled glass micropipettes with a beveled tip (inner diameter of tip: $\sim 20 \mu \mathrm{m}$ ) using pressure injection via a micropump (World Precision Instruments). Total injection volumes ranged from 40 to 100 $\mathrm{nl}$, at $15 \mathrm{nl} / \mathrm{min}$. Following injection, the micropipette was left in place for $\sim 5 \mathrm{~min}$ to minimize diffusion of virus into the pipette path. After withdrawing the micropipette, the scalp was sutured closed and animals were administered Ketofen $(5 \mathrm{mg} / \mathrm{kg})$ to minimize inflammation and discomfort. Animals were recovered from anesthesia on a heating pad and then returned to their home cage.

For spinal injections of AAVretro-hSyn-GFP and AAVretro-hSynCre or AAV1-hSyn-GFP and AAV1-CAG-tdTomato (see Fig. 5A,B), mice were anesthetized and positioned into a stereotaxic frame. Cervical and lumbar injections were performed sequentially in the same procedure using aseptic technique. For each injection, a small patch of skin above the cervical or lumbar spinal region was shaved and a small incision was made to expose underlying muscle tissue. Muscle was blunt dissected and retracted to expose cervical (near C7-C8) or lumbar (near L3L4) vertebrae and the spinal cord was stabilized using notched bars (Kopf, model 987). Virus was injected unilaterally (200 nl total volume, $15 \mathrm{nl} / \mathrm{min}$ ) between vertebral segments using a pulled glass micropipette with a beveled tip (inner diameter of tip: $\sim 20 \mu \mathrm{m}$ ) at a depth of $0.7 \mathrm{~mm}$ from the dorsal surface of the spinal cord. After withdrawing the micropipette, the skin was sutured closed and animals were recovered from anesthesia on a heating pad. To minimize inflammation and discomfort, animals were administered Ketofen $(5 \mathrm{mg} / \mathrm{kg})$ at the beginning of the surgical procedure and again every $24 \mathrm{~h}$ for $4 \mathrm{~d}$ following surgery.

\section{Injection of viruses for anterograde transneuronal labeling}

To compare the anterograde transneuronal transport properties of different viruses (Fig. 6A-D), self-complementary (sc) AAV1-hSyn-Cre (Vigene Biosciences; $2.8 \times 1013 \mathrm{GC} / \mathrm{ml}$ ), AAV1-hSyn-Flp (Vigene Biosciences; $5.5 \times 1013 \mathrm{GC} / \mathrm{ml}$ ), AAVretro-hSyn-Cre (Vigene Biosciences; $1.5 \times 1014 \mathrm{GC} / \mathrm{ml}$ ), AAVPHP.B-CMV-Cre (SignaGen; $2.3 \times 1013 \mathrm{GC} /$ $\mathrm{ml}$ ), Adenovirus (Ad5-CMV-Cre; Kerafast, $3.0 \times 1012 \mathrm{GC} / \mathrm{ml}$ ), VSVGpseudotyped lentivirus (LV-CMV-Cre; Cellomics Tech; $1.0 \times 108 \mathrm{GC} /$ $\mathrm{ml}$ ), VSVG-pseudotyped Baculovirus (BAC-CMV-Cre; University of Iowa; $3.7 \times 1010 \mathrm{GC} / \mathrm{ml}$ ), or G-deleted Rabies virus (RAV-Cre-GFP; Salk Institute; $8.6 \times 108 \mathrm{GC} / \mathrm{ml})$ was injected into V1 (60 $\mathrm{nl}$ total volume; coordinates from bregma: anteroposterior $-3.9 \mathrm{~mm}$, mediolateral $2.6 \mathrm{~mm}$, depth $0.5 \mathrm{~mm}$ ) of Ai14 mice (for Cre-expressing viruses) or Frt-GFP mice (for AAV1-hSyn-Flp). Original titers were used for each virus injection. Animals were euthanized 4 weeks following injection and postsynaptic structures were examined for the presence of cell body labeling. The number of tdTomato + cells in superior colliculus (SC) was quantified (see Imaging and Quantification) for each virus injection and plotted alongside previously reported data for additional viruses (see Fig. 6D; Zingg et al., 2017). The scAAV1hSyn-Cre contains a double-stranded, rather than single-stranded, DNA construct and was initially tested for any potential enhancement in anterograde transsynaptic transduction efficiency (McCarty, 2008). We observed a modest increase in labeling relative to other comparable single-stranded AAV1 constructs (e.g., AAV1-CMV-Cre or AAV1-hSyn-Flp; Fig. 6D), however, its efficiency was only half that of constructs containing the woodchuck hepatitis post-transcriptional regulatory element (WPRE). This enhancer element can increase viral gene expression by sevenfold (Loeb et al., 1999), however, we found that overexpression of Cre can become toxic to host cells at the injection site (see Fig. 6A-C). We therefore opted to use vectors without WPRE, despite their reduced efficiency, because these did not exhibit signs of toxicity at the injection site (for additional information, see Haery et al., 2019).

To demonstrate retrograde and anterograde transneuronal spread of AAV1 within the same pathway (see Fig. $6 E-I$ ), we injected primary auditory cortex (A1; coordinates from bregma: anteroposterior $-2.9 \mathrm{~mm}$, mediolateral $4.5 \mathrm{~mm}$, depth $0.6 \mathrm{~mm}$ ) or inferior colliculus (IC; coordinates from bregma: anteroposterior $-5.3 \mathrm{~mm}$, mediolateral $0.8 \mathrm{~mm}$, depth $0.5 \mathrm{~mm}$ ) with either scAAV1-hSyn-Cre or AAVretro-hSyn-Cre ( $80 \mathrm{nl}$ total volume, titer of both viruses adjusted to $2.8 \times 1013 \mathrm{GC} / \mathrm{ml}$ ) in Ail4-tdTomato mice. Animals were euthanized 2 weeks following injection and the number of retrogradely labeled tdTomato + cells in A1 or anterograde transsynaptically labeled cells in IC were quantified (see Imaging and Quantification).

To test for the specificity of viral spread to different cell types in the cerebellum, scAAV1-hSyn-Cre was injected into the pontine nucleus (PN; $80 \mathrm{nl}$ total volume; coordinates from bregma: anteroposterior -3.9 $\mathrm{mm}$, mediolateral $0.4 \mathrm{~mm}$, depth $5.5 \mathrm{~mm}$ ) or inferior olive (IO; $80 \mathrm{nl}$ total volume; coordinates from bregma: anteroposterior $-6.6 \mathrm{~mm}$, 
mediolateral $0.4 \mathrm{~mm}$, depth $5.5 \mathrm{~mm}$ ) in Ail4 mice crossbred with GAD67-GFP mice (from Yuchio Yanagawa, Brain Science Institute, RIKEN, Japan). Animals were euthanized 2 weeks following injection and the cerebellar cortex (CB) was examined for the presence of tdTomato + cell body labeling in the molecular, granule, and Purkinje cell layers.

To examine the efficiency of anterograde transsynaptic spread across different types of synapses, scAAV1-hSyn-Cre injections were targeted to inhibitory projection neurons or neuromodulatory cell populations in Ail4 mice. To test for viral spread through inhibitory synapses onto downstream inhibitory neurons, scAAV1-hSyn-Cre was injected into the striatum (Str; $100 \mathrm{nl}$ total volume; coordinates from bregma: anteroposterior $+0.5 \mathrm{~mm}$, mediolateral $2.3 \mathrm{~mm}$, depth $3.0 \mathrm{~mm}$ ) and the substantia nigra, pars reticulata $(\mathrm{SNr})$ was examined for cell body labeling ( 2 week postinjection survival time). To confirm the $\mathrm{Str} \rightarrow \mathrm{SNr}$ projection pathway is unidirectional, G-deleted Rabies-GFP (Salk Institute; $5.5 \times 108 \mathrm{GC} / \mathrm{ml}$ ) was injected into the Str and the substantia nigra, pars compacta $(\mathrm{SNc})$ and $\mathrm{SNr}$ were examined for the presence of retrogradely labeled GFP + cell bodies ( $50 \mathrm{nl}$ injection, 1 week postinjection survival time). To test for viral spread through inhibitory synapses onto presumed excitatory neurons, $\mathrm{SNr}$ was injected with scAAV1-hSyn-Cre (50 $\mathrm{nl}$ total volume; coordinates from bregma: anteroposterior $-3.3 \mathrm{~mm}$, mediolateral $1.6 \mathrm{~mm}$, depth $4.3 \mathrm{~mm}$ ) and downstream neurons in ventromedial nucleus of the thalamus (VM) were examined for the presence of tdTomato + labeling ( 2 week postinjection survival time). To test for viral spread through neuromodulatory synapses, scAAV1-hSyn-Cre was injected ( $80 \mathrm{nl}$ total volume, 2 week postinjection survival time) into the diagonal band nucleus (NDB; cholinergic neurons, coordinates from bregma: anteroposterior $+0.5 \mathrm{~mm}$, mediolateral $2.0 \mathrm{~mm}$, depth $5.0 \mathrm{~mm}$, $11^{\circ}$ angle), dorsal raphe (DR; serotonergic neurons, coordinates from bregma: anteroposterior $-4.5 \mathrm{~mm}$, mediolateral $2.0 \mathrm{~mm}$, depth $3.2 \mathrm{~mm}$, $30^{\circ}$ angle), or locus ceruleus (LC; noradrenergic neurons, coordinates from bregma: anteroposterior $-5.4 \mathrm{~mm}$, mediolateral $0.8 \mathrm{~mm}$, depth 3.1 $\mathrm{mm}$ ) of Ail4 mice and unidirectionally connected downstream targets were examined for cell body labeling [e.g., V1 for NDB and LC, or dorsolateral geniculate nucleus (LGNd) and lateral entorhinal cortex (ENTl) for DR]. To demonstrate the location and axonal targeting of V1-projecting cholinergic or LGNd-projecting serotonergic cell populations, AAV1-CAG-FLEX-GFP-WPRE (Addgene; $1.7 \times 1013 \mathrm{GC} / \mathrm{ml}$ ) was injected ( $60 \mathrm{nl}$ total volume, 3 week postinjection survival time) into NDB of Chat-IRES-Cre mice (Jackson Laboratories, stock \#006410) or DR of Pet1-Cre mice (Jackson Laboratories, stock \#012712).

To label different input-defined cell populations in the spinal cord, descending pathways in the brain were first identified by injecting AAVretro-hSyn-Cre $(1.5 \times 1014 \mathrm{GC} / \mathrm{ml}, 200 \mathrm{nl}$; Vigene Biosciences $)$ and AAVretro-hSyn-GFP $(1.7 \times 1014 \mathrm{GC} / \mathrm{ml}, 200 \mathrm{nl}$; Vigene Biosciences $)$ unilaterally into the left cervical (C7-C8) and lumbar (L3-L4) spinal cord, respectively. Animals were euthanized 3 weeks following injection and the entire brain was examined for retrogradely labeled GFP+ and/or tdTomato + cell bodies. Candidate regions were then crossexamined for the presence or absence of ascending spinal axon terminals following cervical and lumbar injections of AAV1-hSyn-GFP and AAV1-CAG-tdTomato, respectively, to validate their unidirectional connection with the spinal cord (200 nl injection volume, 3 week postinjection survival time; see Fig. $5 B$ ). Spinal-projecting brain regions lacking ascending spinal axon terminals were then selected for injection of scAAV1-hSyn-Cre (100 nl total volume) in Ai14 mice using the following coordinates from bregma: lower-limb-related primary motor cortex (MOp-11; anteroposterior $-0.8 \mathrm{~mm}$, mediolateral $1.3 \mathrm{~mm}$, depth $0.6 \mathrm{~mm}$ ); lower-limb-related somatosensory cortex (SSp-ll; anteroposterior $-0.9 \mathrm{~mm}$, mediolateral $1.7 \mathrm{~mm}$, depth $0.6 \mathrm{~mm}$ ); lateral hypothalamic area (LHA; anteroposterior $-1.5 \mathrm{~mm}$, mediolateral $1.3 \mathrm{~mm}$, depth $5.1 \mathrm{~mm}$ ); and red nucleus (RN; anteroposterior $-3.5 \mathrm{~mm}$, mediolateral $0.5 \mathrm{~mm}$, depth $3.7 \mathrm{~mm}$ ). Following a 2 week postinjection survival time, animals were euthanized and cervical, thoracic, and lumbar segments of the spinal cord were examined for tdTomato + cell body labeling.

To reveal the topographical distribution of cells downstream of two different corticofugal pathways in the same brain, AAV1-hSyn-Flp was injected into MOp-ul (100 nl total volume, coordinates from bregma: anteroposterior $+0.7 \mathrm{~mm}$, mediolateral $1.7 \mathrm{~mm}$, depth $0.6 \mathrm{~mm}$ ); and scAAV1-hSyn-Cre was injected into MOp-1l (100 nl total volume, anteroposterior $-0.8 \mathrm{~mm}$, mediolateral $1.3 \mathrm{~mm}$, depth $0.6 \mathrm{~mm}$ ) in Ail4tdTomato x Frt-GFP mice. Following a 2 week postinjection survival time, downstream targets across the entire brain and spinal cord were examined for $\mathrm{Flp}+/ \mathrm{GFP}+$ and $\mathrm{Cre}+/ \mathrm{Tom}+$ cell body labeling.

To label the axonal output of $\mathrm{PN}$ neurons that specifically receive input from upper limb- or lower limb-related MOp, scAAV1-hSyn-Cre was injected into MOp-ul ( $80 \mathrm{nl}$ total volume) or MOp-ll and AAV1CAG-Flex-GFP was injected into PN (80 nl total volume, coordinates from bregma: anteroposterior $-3.9 \mathrm{~mm}$, mediolateral $0.4 \mathrm{~mm}$, depth 5.5 $\mathrm{mm}$ ) in Ail4 mice. Following a 2 week postinjection survival time, animals were euthanized and the cerebellum was examined for GFP+ axons.

\section{Tetanus toxin expression}

To explore underlying mechanisms of AAV transneuronal release, tetanus toxin light chain was expressed in V1 of Ai14 mice using injections of AAV $\mathrm{DJ}^{-\mathrm{CMV}-T e N T-P 2 A-G F P}$ (Stanford Viral Core; $5.7 \times 1012 \mathrm{GC} /$ $\mathrm{ml}, 100 \mathrm{nl}$ total volume, $n=8 \mathrm{mice}$ ). As a control, a separate group of Ail4 mice were injected with AAV1-hSyn-GFP-WPRE (Addgene; titer reduced to $3.2 \times 1012 \mathrm{GC} / \mathrm{ml}, 100 \mathrm{nl}$ total volume, $n=8$ mice). Following 2 weeks to allow for sufficient viral gene expression, scAAV1$\mathrm{hSyn}$-Cre was injected into the same location in V1 for each group (60 $\mathrm{nl}$ total volume). After an additional 2 weeks postinjection, mice were euthanized and SC was examined for the presence of tdTomato + cell body labeling. To establish a time course for tetanus toxin light chain (TeNT) expression and its effect on anterograde transsynaptic spread of AAV1, we injected $A A V_{\mathrm{DJ}^{-}} \mathrm{CMV}-\mathrm{TeNT}-\mathrm{P} 2 \mathrm{~A}-\mathrm{GFP}$ into V1 of Ai14 mice, and then followed up with injections of scAAV1-hSyn-Cre either within the same surgical procedure (coinjection), $2 \mathrm{~d}$ after initial viral injection, or $6 \mathrm{~d}$ after initial viral injection ( $n=4$ mice for each group). All animals were euthanized 2 weeks after receiving the second virus injection and SC was examined for the presence of tdTomato + cell bodies.

\section{Virus injections for sparse labeling of neurons}

To achieve sparse labeling in a given Cre-expressing cell population, a coinjection strategy was used to obtain robust levels of YFP expression in only a few cells. Coinjections consisted of a 1:1 mixture of high titer $\mathrm{AAV}_{\mathrm{DJ}^{-}}$-EF1a-fDIO-YFP-WPRE (UNC Vector core; final titer $1.2 \times 1013$ GC/ml) and low titer AAV1-EF1a-DIO-Flp-WPRE (Vigene Bioscience; diluted within a final titer range of $7.5 \times 108-1010 \mathrm{GC} / \mathrm{ml}$ ). To establish a relationship between titer and the resulting number of labeled cells, AAV1-EF1a-DIO-Flp-WPRE was diluted to either $7.5 \times 108,10^{9}$, or $10^{10} \mathrm{GC} / \mathrm{ml}$ and coinjected with $\mathrm{AAV}_{\mathrm{DJ}^{-}}$EF1a-fDIO-YFP-WPRE $(50 \mathrm{nl}$ total volume) in V1 of Ai14 x PV-Cre mice (Jackson Laboratories, stock \# 017320; $n=4$ mice for each titer). Following a 2 week postinjection survival time, animals were euthanized and V1 was examined for YFP+ cell labeling.

To achieve sparse labeling of both input- and genetically-defined cell populations, AAV1-EF1a-DIO-Flp-WPRE was injected at reduced titer $(1.5 \times 1012 \mathrm{GC} / \mathrm{ml}, 80 \mathrm{nl}$ injection volume $)$ into anterior cingulate cortex (ACA; coordinates from bregma: anteroposterior $+0.5 \mathrm{~mm}$, mediolateral $0.3 \mathrm{~mm}$, depth $0.9 \mathrm{~mm}$ ) in Ai14 x Vglut2-Cre mice (Jackson Laboratories, stock \#016963). This titer was chosen as previous results (Zingg et al., 2017) revealed the number of anterograde transsynaptically labeled cells in a given target region are reduced by $85-90 \%$ when injection titer is lowered from 1013 to $1012 \mathrm{GC} / \mathrm{ml}$. A test injection of scAAV1-hSyn-Cre ( $80 \mathrm{nl}$ volume, $1.5 \times 1013 \mathrm{GC} / \mathrm{ml}$ ) in ACA of Ail $4 \mathrm{x}$ GAD67-GFP mice revealed an average of $\sim 8$ GAD67-GFP+/Tom + cells and 35 GAD67-GFP-/Tom + cells (presumed excitatory) within a given $300 \mu^{3}$ sample space of dorsolateral periaqueductal gray (PAGdl). A reduced titer injection of AAV1-EF1a-DIO-Flp-WPRE $(1.5 \times 1012 \mathrm{GC} / \mathrm{ml}, 80 \mathrm{nl}$ injection volume $)$ in ACA of Vglut2-Cre mice would then be expected to tag $\sim 4$ Vglut2-Cre+/Flp + cells per $300 \mu \mathrm{m}^{3}$ region of PAGdl. To robustly label these cells for morphologic analysis, injections of $\mathrm{AAV}_{\mathrm{DJ}}$-EF1a-fDIO-YFP-WPRE (30 nl total volume, $2.5 \times 1013 \mathrm{GC} / \mathrm{ml}$ ) were targeted to the PAGdl (coordinates relative to 
A

Synaptic specificity of spread?

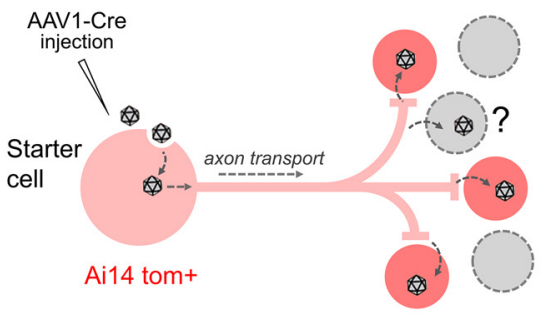

C

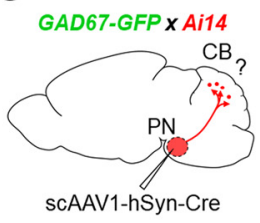

Pontine nucleus
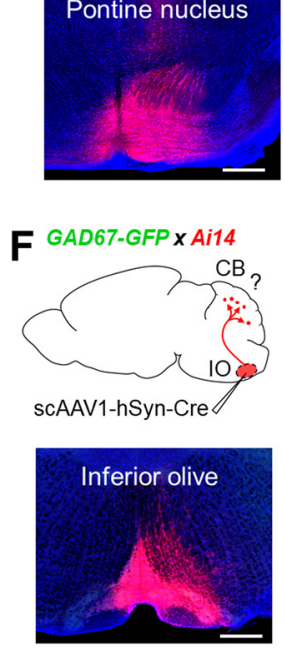

\section{D}
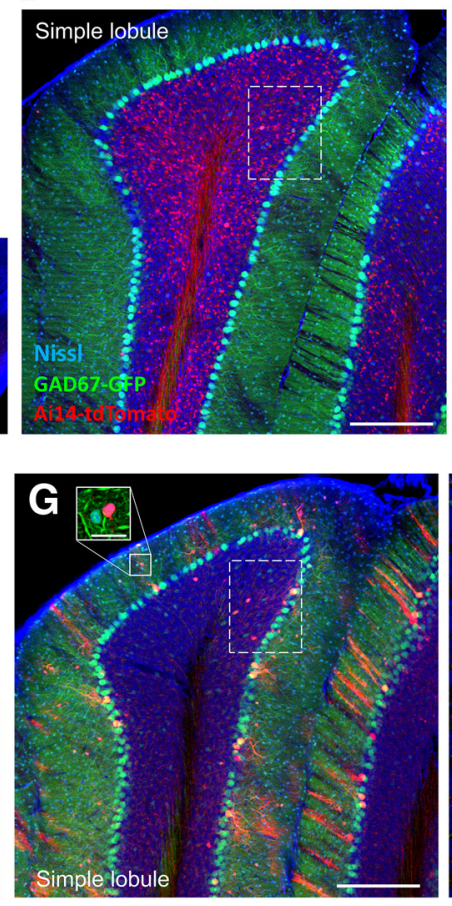

B

Anatomical test of specificity

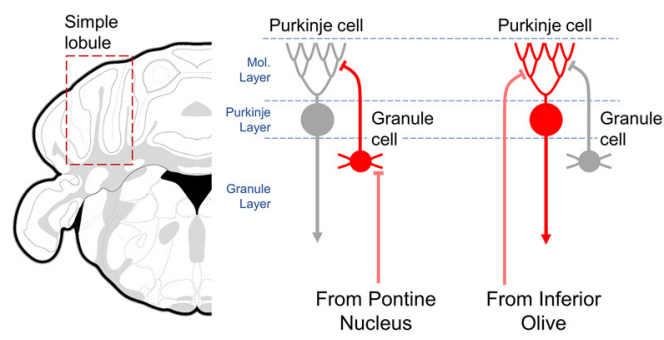

E
I
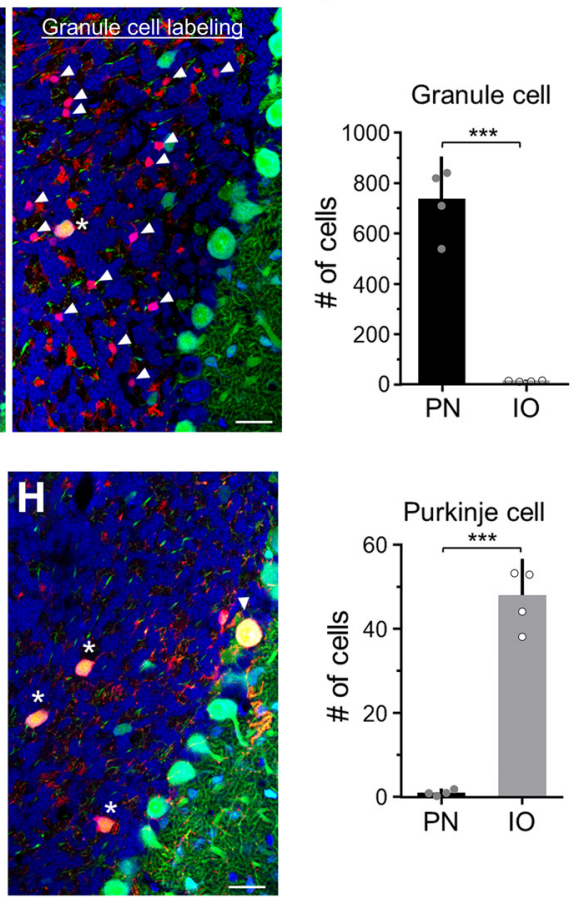

Figure 1. Anatomical evidence for the synaptic specificity of viral spread. A, lllustration shows that following injection in an upstream brain region, AAV1-Cre is transported down axons and may be released through the synapse to transduce postsynaptically connected neurons (red cells, in (re-dependent tdTomato background). The extent to which extra-synaptic release of virus may contribute to the local transduction of unconnected cell types (gray cells) remains unclear. $\boldsymbol{B}$, Strategy for testing the synaptic specificity of viral spread in an anatomically defined circuit. Postsynaptic labeling was examined in the simple lobule of the CB following injections in the inferior olive or PN (left). Mossy fiber afferents from the PN are known to innervate GCs but not PCs (right). On the other hand, climbing fiber afferents from the 10 pass through the granule layer and selectively innervate PCs, but not GCs. Locations of cell bodies in different layers of the CB are indicated by dashed lines (molecular layer, Purkinje layer, or granule layer). C, Approach for labeling neurons postsynaptic to mossy fibers in the CB. The scAAV1-hSyn-Cre was injected into the PN of Ai14 x GAD67-GFP transgenic mice. Bottom, Example injection site (red). Blue, fluorescent Nissl stain. Scale bar, $500 \mu \mathrm{m}$. D, A coronal section through simple lobule showing pontine afferents and postsynaptic neurons labeled in the granule layer of the cerebellum (red). GAD67-GFP+ PCs and molecular layer interneurons are labeled in green. Blue, Fluorescent Nissl stain. Scale bar, $250 \mu \mathrm{m}$. E, Higher-magnification view of the dashed region shown in $\boldsymbol{D}$. TdTomato +/GFP - GCs (red; costained with Nissl, blue, arrowheads) and mossy fiber terminals (red) were observed in the granule layer, along with large GAD67-GFP+ neurons (yellow, asterisk). Scale bar, $25 \mu \mathrm{m}$. $\boldsymbol{F}$, Approach for labeling neurons postsynaptic to climbing fibers in CB. The scAAV1-hSyn-Cre was injected into the 10 of Ai14 x GAD67-GFP mice. Bottom, Example injection site (red). Scale bar, $500 \mu \mathrm{m}$. G, Climbing fiber afferents and postsynaptic neurons (red) labeled in the granule, Purkinje, and molecular layers of the simple lobule. Most labeled neurons in the granule cell layer colocalized with GAD67-GFP+ expression. Scale bar, $250 \mu \mathrm{m}$. Solid box shows close up of a MLI. Scale bar, $25 \mu \mathrm{m}$. $\boldsymbol{H}$, Higher-magnification view of the dashed region shown in $\mathbf{G}$. Cre +/tdTomato $+/$ GFP + neurons were observed in the granule layer (yellow, asterisks), Purkinje cell layer (yellow, arrowhead), and molecular layer (cells shown in G). $I$, Quantification of the total number of GCs (top) and PCs (bottom) counted across four sections of the simple lobule for each animal injected in PN or 10 (mean plotted for $n=4$ animals for each pathway). Error bar $=S D$. ${ }^{* * *} p<0.001, t$ test.

bregma: anteroposterior $-4.0 \mathrm{~mm}$, mediolateral $0.6 \mathrm{~mm}$, depth 2.3 $\mathrm{mm}$ ). Following a 2 week postinjection survival, animals were euthanized and PAGdl was examined for the presence of YFP + cell bodies.

\section{Histology}

Following desired postinjection survival time, animals were deeply anesthetized and transcardially perfused with $4 \%$ paraformaldehyde. Brains were extracted and postfixed for $24 \mathrm{~h}$ at $4^{\circ} \mathrm{C}$ in $4 \%$ paraformaldehyde and then sliced into $150 \mu \mathrm{m}$ sections using a vibratome (Leica, VT1000s). The sections were serially mounted onto glass slides and coverslipped. For some experiments, a fluorescent Nissl stain was added (NeuroTrace 640, ThermoFisher, N21483) to reveal cell body location and cytoarchitectural information.

\section{Imaging and quantification}

All images were generated using a confocal microscope (Olympus FluoView FV1000). To quantify cells labeled in the cerebellum following AAV1-Cre injection in PN or IO (Fig. 1), coronal sections across the entire cerebellum were collected and the contralateral simple lobule (SIM) was selected for quantification as it exhibited strong and consistent labeling in all examined cases. For each animal, $10 \times$ magnification images were collected for four sections of SIM (from $\sim-5.8$ to -6.4 $\mathrm{mm}$ posterior to bregma) across the depth of the tissue (150 $\mu \mathrm{m}$ thickness, $15 \mu \mathrm{m} z$-stack interval). TdTomato + neurons were quantified in the molecular layer, Purkinje cell layer, and large GAD67-GFP+/Tom+ cells were identified in the granule layer. To distinguish tdTomato+ granule cells (GCs) from mossy fiber terminals, $40 \times z$-stack images were collected throughout the granule layer and tdTomato + cell bodies that colocalized with fluorescent Nissl stain were manually identified and 
counted. Cell counts for all four sections were totaled for each animal and plotted as mean $\pm \mathrm{SD}$ ( $n=4$ mice for both $\mathrm{PN}$ and IO). To provide a quantitative estimate of viral leakage, we counted the total number of Nissl+ granule cells (average of 13480 cells) and Purkinje cells (average of 472 cells) found in four sections of the SIM lobule. Assuming the extreme case in which the virus may spread by leaking from any part of the axon in the target region, we applied the following formula that takes into consideration the relative probability of labeling each cell type given their differences in density: $\mathrm{PN} \rightarrow \mathrm{CB} \%$ leakage $=[$ (leaky labeled PCs)/(Total PCs) $] /[($ labeled GCs)/(Total GCs) $] \times 100$ and $\mathrm{IO} \rightarrow \mathrm{CB} \%$ leakage $=[($ leaky labeled GCs $) /($ Total GCs $)] /[$ (labeled $\mathrm{PCs}) /($ Total PCs $)] \times 100$, where GCs and PCs refer to granule cells and Purkinje cells, respectively, and the values for "leaky labeled" and "labeled" cells are taken from tdTomato+ cell counts reported for each pathway in Figure $1 I$.

To quantify the total number of cell bodies labeled in SC following virus injections in V1 (see Figs. $3 D, 6 D$ ), serial sections across the entire structure were collected and examined. Regions with labeled cells were imaged at $10 \times$ magnification across the depth of the tissue $(150 \mu \mathrm{m}$ thickness, $15 \mu \mathrm{m} z$-stack interval). TdTomato + cell bodies that colocalized with fluorescent Nissl stain were manually identified and counted.

To provide an estimate of the efficiency of viral spread across different types of synapses (see Fig. 4), the percentage of tdTomato + cells relative to Nissl+ cells was quantified within the axon terminal field in either $\mathrm{SNr}$ (for striatum injections) or VM (for SNr injections). For diffuse neuromodulatory output targeting entire structures or cortical regions, the percentage of tdTomato + cells was quantified in relation to the total number of Nissl+ cells in the LGNd (for DR injections) or the total number of tdTomato + cells relative to Nissl + cells within a $500 \times 500 \mu \mathrm{m}$ sample space in V1 (for NDB and LC injections). $40 \times$ magnification images were used for quantification, and an average percentage was generated for each animal using at least 4 sample images in the target region ( $n=4$ mice for each pathway).

To quantify the number of anterograde transsynaptically labeled cells in different segments of the spinal cord (see Fig. 5), six coronal sections (150 $\mu \mathrm{m}$ thickness) were selected at $450 \mu \mathrm{m}$ intervals apart for each of the cervical, thoracic, and lumbar regions. Sections were then imaged using a confocal microscope at a single $z$-plane at $10 \times$ magnification and tdTomato + cell bodies were manually identified and counted. Cell counts were plotted as mean $\pm \mathrm{SD}$ for each spinal region $(n=1$ mouse for each of the four pathways tested).

To compare the retrograde transport efficiency of AAV1-Cre with that of AAVretro-Cre (see Fig. 6H), three consecutive coronal sections through A1 ( -2.5 to $-3.0 \mathrm{~mm}$ posterior from bregma) were imaged at a single $z$-plane at $10 \times$ magnification, and tdTomato + cell bodies were manually quantified within a fixed $1 \mathrm{~mm}^{2}$ region-of-interest centered on the highest density of labeling for each section. The average number of cells per section was reported for each animal $(n=3$ mice for each group). Similarly, to quantify the number of anterograde transsynaptically labeled cells in IC following injections of either scAAV1-hSyn-Cre or AAVretro-hSyn-Cre in A1 (see Fig. 6I), three consecutive coronal sections through IC were imaged in a single $z$-plane at $10 \times$ magnification $(-5.1$ to $-5.6 \mathrm{~mm}$ posterior from bregma). TdTomato + cell bodies were then manually quantified within a fixed $1 \mathrm{~mm}^{2}$ region of interest to generate an average number of cells per section for each animal $(n=3$ mice for each group).

To provide an estimate of the difference in axonal projections to the cerebellum from MOp-ul-versus MOp-ll-recipient PN neurons, the density of axon terminals was measured within the two major targets of each pathway [paramedian (PRM) and contralateral copula pyramidis (COP) lobules; see Fig. 8]. Five consecutive coronal sections $(150 \mu \mathrm{m}$ thickness) through the posterior cerebellum $(-7.1$ to $-7.8 \mathrm{~mm}$ from bregma) were imaged at $10 \times$ magnification for each mouse. Using Photoshop, $3 \times$ the average background signal was removed from each image and the remaining signal was rendered binary. The total number of pixels corresponding to axonal fluorescence was then quantified and expressed as a fraction of the total pixel count in the granule layer of PRM or COP for each section. The average density of axon signal in each lobule was determined for each pathway and reported as the mean $\pm \mathrm{SD}$ for each group ( $n=3$ mice per group).
To quantify the number of sparsely labeled YFP+/Tomato + parvalbumin (PV) cells in V1 following coinjections of AAV-fDIO-YFP and low titer AAV-DIO-Flp (see Fig. 9), serial sections through V1 were collected and imaged at $10 \times$ magnification across the depth of the tissue (150 $\mu \mathrm{m}$ thickness, $15 \mu \mathrm{m} z$-stack interval). The total number of YFP + / Tom + cells were manually identified and counted for each of the titers tested ( $n=4$ animals each).

\section{Slice preparation and recording}

To compare the rate of synaptic connectivity between tdTomato + , and neighboring non-labeled neurons in IC, a 1:1 mixture of scAAV1-hSynCre and AAV1-EF1a-DIO-hChR2-YFP (Addgene; $1.6 \times 1013 \mathrm{GC} / \mathrm{ml}$ ) was injected into A1 of Ail 4 mice (100 nl total volume, coordinates from bregma: anteroposterior $-3.1 \mathrm{~mm}$, mediolateral $4.5 \mathrm{~mm}$, depth 0.7 $\mathrm{mm}$ ). Following a 2 week postinjection survival time, acute brain slices containing IC were prepared. Following urethane anesthesia, the animal was decapitated and the brain was rapidly removed and immersed in an ice-cold dissection buffer (composition in mM: $60 \mathrm{NaCl}, 3 \mathrm{KCl}, 1.25$ $\mathrm{NaH}_{2} \mathrm{PO}_{4}, 25 \mathrm{NaHCO}_{3}, 115$ sucrose, 10 glucose, $7 \mathrm{MgCl}_{2}, 0.5 \mathrm{CaCl}_{2}$; saturated with $95 \% \mathrm{O}_{2}$ and $5 \% \mathrm{CO}_{2}$, pH 7.4). Brain slices of $350 \mu \mathrm{m}$ thickness containing IC were cut in a coronal plane using a vibrating microtome (Leica VT1000s). Slices were allowed to recover for $30 \mathrm{~min}$ in a submersion chamber filled with warmed $\left(35^{\circ} \mathrm{C}\right) \mathrm{ACSF}$ and then to cool gradually to room temperature until recording. The spatial expression pattern of channelrhodopsin2 (ChR2)-EYFP in each slice was examined under a fluorescence microscope before recording. IC neurons were visualized with IR-DIC and fluorescence microscopy (Olympus BX51 WI) for specific targeting of both tdTomato + neurons and nearby (within $150 \mu \mathrm{m}$ ) tdTomato- neurons surrounded by EYFP+ fluorescent fibers. Patch pipettes (Kimax) with $\sim 4-5 \mathrm{M} \Omega$ impedance were used for whole-cell recordings. Recording pipettes contained the following (in $\mathrm{mm}$ ): $130 \mathrm{~K}$-gluconate, $4 \mathrm{KCl}, 2 \mathrm{NaCl}, 10 \mathrm{HEPES}, 0.2 \mathrm{EGTA}, 4 \mathrm{ATP}, 0.3$ GTP, and 14 phosphocreatine, $\mathrm{pH} 7.25 ; 290 \mathrm{mOsm}$. Signals were recorded with an AxoPatch 200B amplifier (Molecular Devices) under voltage-clamp mode at a holding voltage of $-70 \mathrm{mV}$ for excitatory currents or $0 \mathrm{mV}$ for inhibitory currents, filtered at $2 \mathrm{kHz}$ and sampled at $10 \mathrm{kHz} .1 \mu \mathrm{M}$ tetrodotoxin (TTX) and $1 \mathrm{~mm} 4$ - aminopyridine (4-AP) was added to the external solution for recording only monosynaptic responses (Petreanu et al., 2009) to blue light stimulation (3-10 ms pulse, $3 \mathrm{~mW}$ power, 10 trials, delivered via a mercury Arc lamp gated with an electronic shutter).

\section{Statistical methods}

All statistical analyses were performed using GraphPad Prism 6. Samples were first determined to have normal distribution using the ShapiroWilk test. To determine a significant association between anterograde transsynaptic labeling and synaptic connectivity (Fig. 2D), $\chi^{2}$ analysis was performed. To test for a significant difference in the number of cerebellar cell types labeled (Fig. 1I), the number of cells found SC in tetanus toxin experiments (Fig. 3D), the number cells found in A1 or IC (see Fig. $6 H, I)$, or the density of axon terminals in different cerebellar lobules (see Fig. 8), an unpaired Student's $t$ test was used. Differences between datasets were considered significant if $p<0.05$. Results for all histograms are expressed as mean $\pm \mathrm{SD}$.

\section{Results}

\section{Synaptic specificity of AAV transneuronal spread}

Previously, we observed that AAV1-Cre spreads only to firstorder downstream neurons in expected target regions, does not leak from axons of passage, and labels neurons that show a high probability of receiving functional presynaptic input (Zingg et al., 2017). These observations are suggestive of a transsynaptic mechanism of spread, however, the extent to which AAV1 passes exclusively through synaptic connections remains uncertain (Fig. 1A). To provide a deeper understanding of the synaptic nature of AAV1 transport, we systematically characterized: (1) the specificity of the spread to only expected cell 

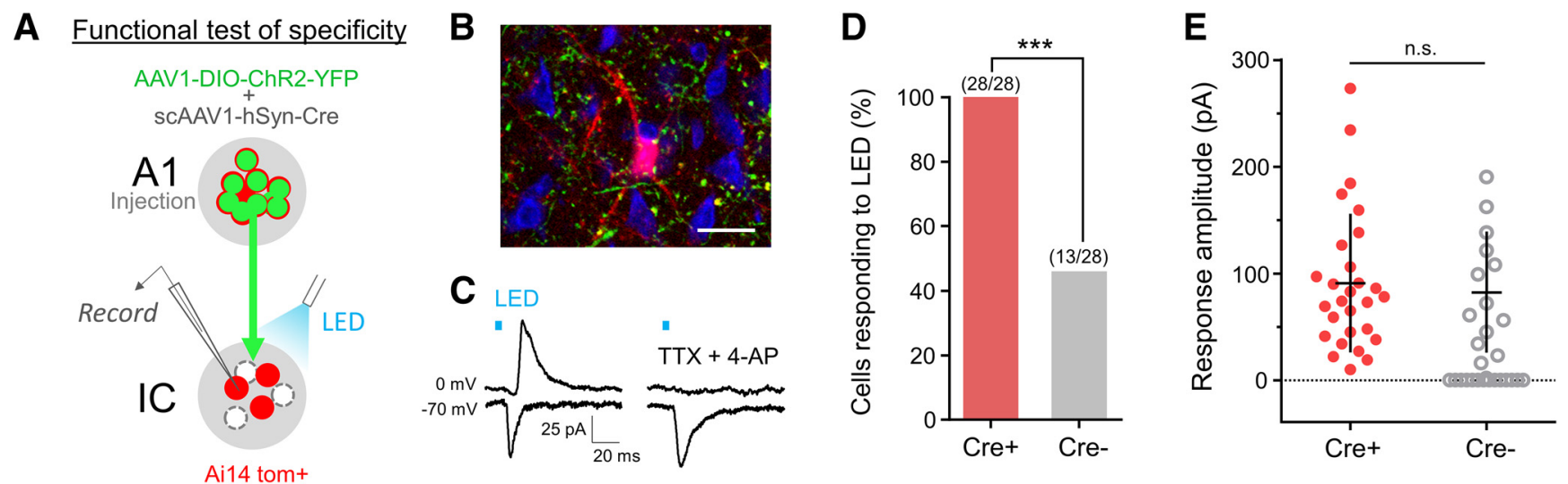

Figure 2. Verification of functional synaptic connectivity. $A$, Strategy for slice recording from transsynaptically labeled neurons in the IC (red) following coinjection of scAAV1-hSyn-Cre and AAV1-DI0-ChR2-YFP into A1. $\boldsymbol{B}$, ChR2-expressing axon terminals (green) surrounding a tdTomato-labeled neuron and neighboring nonlabeled neurons (blue, Nissl stain). Scale bar, 25 um. $\boldsymbol{C}$, Average LED-evoked excitatory (recorded at $-70 \mathrm{mV}$ ) and inhibitory $(0 \mathrm{mV})$ currents in an example tdTomato + IC neuron before (left) and after (right) perfusing in TTX and 4-AP. LED stimulation is marked by a blue bar. $\boldsymbol{D}$, Fraction of transsynaptically labeled (red) and neighboring nonlabeled (gray) neurons showing monosynaptic excitatory currents in response to LED stimulation. ${ }^{* * *} p<0.001, \chi^{2}$ test, 28 cells in each group. $\boldsymbol{E}$, Summary of amplitudes of average monosynaptic excitatory currents evoked by LED for all labeled (red) and nonlabeled (gray) recorded neurons (neurons showing zero currents were excluded). Error bar $=$ SD. There is n.s., no significance, unpaired $t$ test.

types in a well-defined circuit, (2) the probability of functional connectivity between labeled and non-labeled cells in a target region, and (3) whether AAV spread is dependent on synaptic vesicle release.

\section{Anatomical examination of synaptic specificity of AAV transneuronal spread}

To provide a broad estimation of the synaptic specificity of AAV1 transneuronal spread, we took advantage of two different unidirectional pathways that converge on distinct cell types within the $\mathrm{CB}$ (Fig. $1 B$ ). Neurons in the PN project to the granule layer of the cerebellum and form well-characterized connections with GCs (Palay and Chan-Palay, 1974). On the other hand, neurons in the IO send axons through the granule layer and terminate primarily onto the dendrites of PCs (Palay and Chan-Palay, 1974; Mathews et al., 2012). We therefore expected injections of AAV1-Cre in the PN to label GCs, but not PCs, and injections in the IO to label PCs, but not GCs. To test this, we first injected scAAV1-hSyn-Cre, which is packaged with a double-stranded DNA construct (see Materials and Methods; see Fig. 6), into the PN or IO of Ai14 x GAD67-GFP mice (Fig. 1C,F). GAD67-GFP expression was used to facilitate identification of PCs and molecular layer interneurons (MLIs), as well as large inhibitory neurons in the granule layer. Following a 2-week postinjection survival time, $\mathrm{PN}$ injections yielded numerous small tdTomato + / GFP - cells in the granule layer (presumed GCs) along with some large tdTomato+/GFP+ neurons (presumed Golgi cells; Kanichay and Silver, 2008; Fig. 1D,E), whereas IO injections labeled PCs, MLIs, and large inhibitory neurons in the granule layer (Fig. 1G,H). To quantify this labeling, we focused on four consecutive sections of the contralateral SIM (see Materials and Methods) and counted the total number of labeled GCs and PCs across all four sections for each animal $(n=4$ animals for both PN and IO). As expected, PN injections labeled a large number of GCs (average 735 cells per animal), whereas IO injections labeled a negligible number of GCs (average 13 cells per animal; Fig. 1I, top). Similarly, IO injections robustly labeled PCs (average 48 cells per animal), whereas PN injections labeled little or no PCs (average 1 cell per animal; Fig. 1I, bottom). Taking into consideration the difference in density of each cell population in the target region (see Materials and Methods), we estimated that for each pathway, the relative probability of nonspecific labeling was $\sim 1-4 \%$ of innervated cells. Thus, despite this potential for viral leakage, anterograde transneuronal transport was overall quite selective in labeling the expected postsynaptic GC or PC populations.

\section{Functional characterization of synaptic specificity of AAV1 transneuronal spread}

To explore the association between anterograde transneuronally labeled neurons and functional connectivity, we injected a 1:1 mixture of scAAV1-hSyn-Cre and AAV1-EF1a-DIO-ChR2-YFP into the A1 of Ai14 mice and performed slice recording from tdTomato + neurons and neighboring tdTomato- neurons in the IC (Fig. 2A). This pathway was selected given its unidirectional nature and robust transneuronal labeling of cells in the target region (see Fig. 6E-I). Expression of ChR2 was restricted to neurons that were cotransduced by scAAV1-Cre and AAV1DIO-ChR2, thus allowing us to activate the same presynaptic neurons that presumably transported scAAV1-Cre to its downstream targets (Fig. 2B), although some additional fraction of Cre $+/ \mathrm{ChR} 2+$ axons that did not have transneuronal spread occurring may be coactivated in this experimental design (see Discussion). Using whole-cell recording, functionally connected IC neurons were identified by their LED-evoked excitatory synaptic responses (Fig. 2C), which persisted in the presence of TTX and 4-AP (Petreanu et al., 2009). Altogether, 100\% of the tdTomato + cells recorded (28/28 cells) exhibited LED-evoked monosynaptic excitatory responses, whereas only $46 \%$ of neighboring tdTomato- cells (13/28 cells) responded to LED (Fig. 2D, $E)$. These results revealed a statistically significant association between tdTomato + labeling and functional connectivity when compared with non-labeled neurons randomly recorded within the same region and functionally demonstrate that AAV1 preferentially spreads to synaptically connected neurons downstream of the injection site.

\section{Dependence on synaptic vesicle release}

How might AAV1 be released from synaptic terminals? Previous studies have shown that, following uptake at the soma, $\sim 14 \%$ of AAV-containing endosomes are actively trafficked down the axon in a kinesin-2-dependent manner (Castle et al., 2014a,b). It 
A
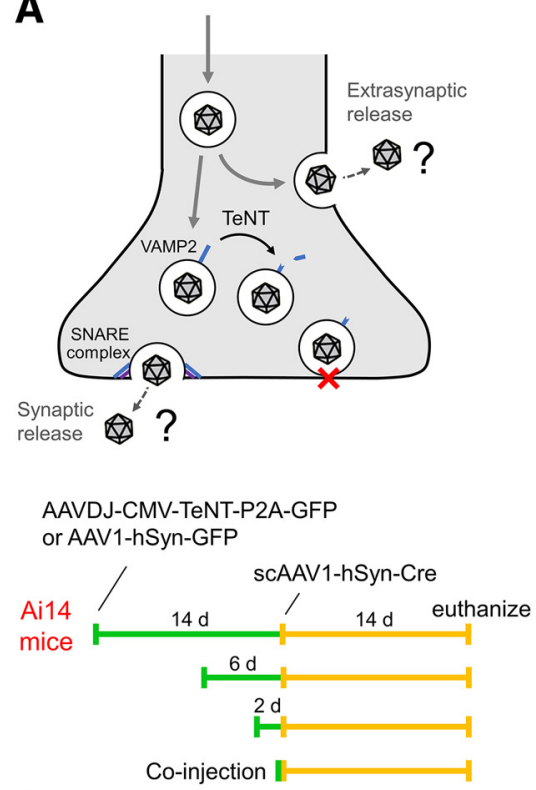

D

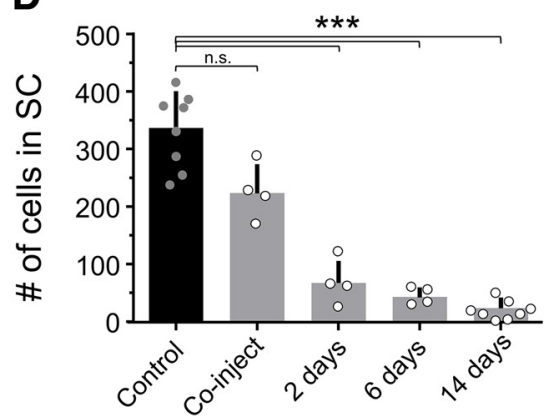

B
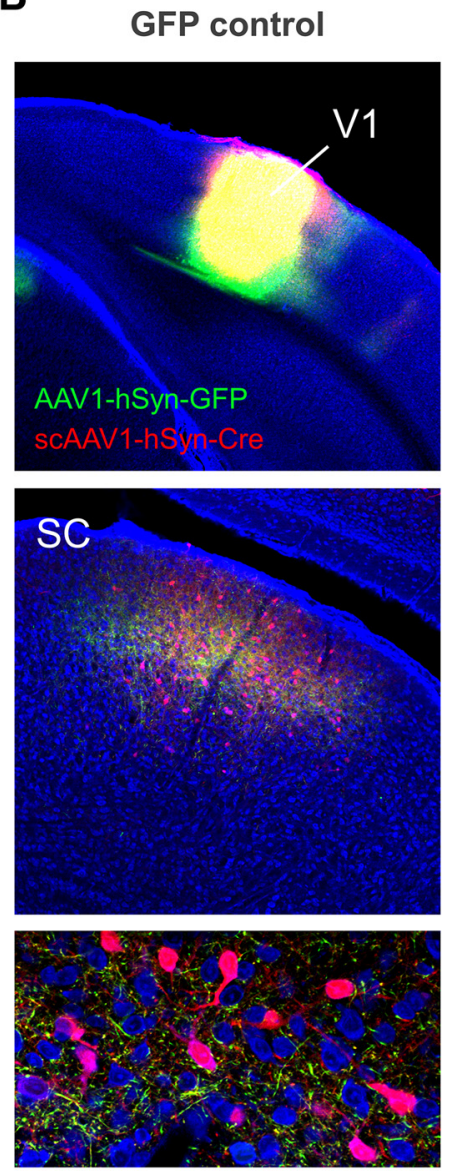

C
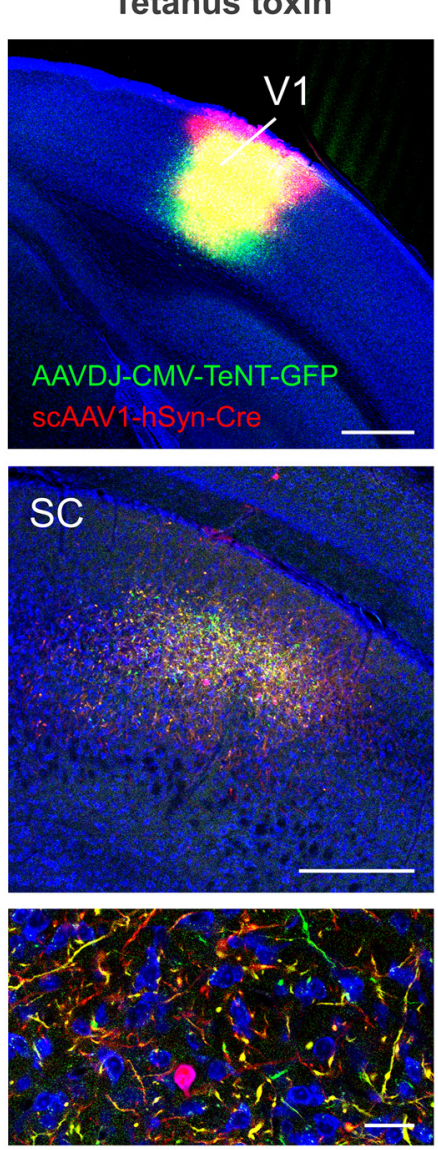

Figure 3. Tetanus toxin inhibition of viral spread. $\boldsymbol{A}$, Experimental design and timeline of virus injections. AAV trafficked to the synapse may be released through synaptic vesicles in a VAMP2-dependent manner (top). Tetanus toxin cleaves VAMP2, preventing synaptic vesicle fusion and potential release of AAV. B, Control experiment. AAV1-hSyn-GFP injection in V1 followed by scAAV1-hSyn-Cre injection 2 weeks later in Ai14 mice (top). 2 weeks after the second injection, GFP + axons (green) and anterograde transsynaptically labeled neurons (red cells) were

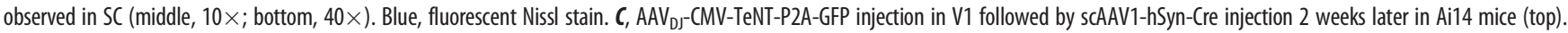
2 weeks after the second injection, GFP+/TeNT+ axons (green) were found in SC, however, very few transsynaptically labeled neurons (red cells) were observed. Scale bars: $\boldsymbol{B}$, $\boldsymbol{C}$, top, $500 \mu \mathrm{m}$; middle, $250 \mu \mathrm{m}$; bottom, $25 \mu \mathrm{m}$. D, Quantification of number of anterograde transsynaptically labeled cells in SC for each injection time point ( $n=8$ mice for control and $14 \mathrm{~d}$ groups, $n=4$ mice for the remaining groups). Error bar $=S D .{ }^{* *} p<0.001$; n.s., no significance, $t$ test.

is possible that some of these may merge with endosomal compartments that give rise to synaptic vesicles, enabling co-release of AAV particles and neurotransmitter into the synaptic cleft (Fig. 3A). To examine the contribution of synaptic vesicle release in viral spread, we expressed TeNT in V1 neurons using injections of $\mathrm{AAV}_{\mathrm{DJ}^{-}} \mathrm{CMV}-\mathrm{TeNT}-\mathrm{P} 2 \mathrm{~A}-\mathrm{GFP}$ (or AAV1-hSyn-GFP as control) in Ail4 mice (Fig. $3 A$ ). TeNT has been shown to completely block $\mathrm{Ca}^{2+}$-evoked synaptic vesicle fusion and transmitter release by cleaving VAMP2 (also known as synaptobrevin-2; Schaivo et al., 1992; Schoch et al., 2001; Yamamoto et al., 2003). Cleavage results in improper SNARE complex formation specifically for synaptic vesicles, while presumably leaving other forms of vesicular fusion intact. Following a 2-week postinjection survival time to allow for TeNT expression, a second injection of scAAV1-hSyn-Cre was targeted to the same location in V1 (Fig. $3 B, C$, top), and SC was then examined 2 weeks later for the presence of tdTomato + cell bodies (Fig. 3B,C, bottom). Remarkably, we observed a $\sim 94 \%$ decrease in the number of transsynaptically labeled (i.e., tdTomato + ) neurons in SC, compared with control animals that received only GFP-expressing AAV1 injection followed by scAAV1-hSyn-Cre injection (Fig. 3D). The remaining fraction of labeled cells observed may be the result of incomplete co-transduction of starter cells with both viruses, and/or may reflect alternative vesicular mechanisms of release that contribute to viral spread. This blockade of anterograde transsynaptic labeling was only significant if the TeNT virus was injected at least $2 \mathrm{~d}$ earlier than AAV1-Cre (Fig. 3D). Last, it is also worth noting that the reduction in labeling of SC neurons was accompanied by noticeable enlargements in TeNT-containing axon terminals (Fig. 3C, bottom), which may reflect a compensatory change following complete block of synaptic vesicle release (Woods et al., 2018). Overall, these results provide additional insight into the synaptic specificity of viral spread and suggest that successful transduction of downstream neurons by AAV1 may favor a synaptic mechanism of vesicle release.

Based on the three lines of evidence presented in the previous sections, we conclude that AAV1 preferentially spreads to synaptically connected neurons in downstream targets, although this spread is not entirely perfect, as some fraction of labeling (estimated to be $\sim 1-4 \%$; Fig. 1 ) may be the result of non-specific viral leakage in the axon terminal region. Given that the majority of cells appear to be postsynaptic to the starter population in our experiments, however, we refer to the transneuronal spread of AAV1 as "transsynaptic" in remaining portions of the text. 

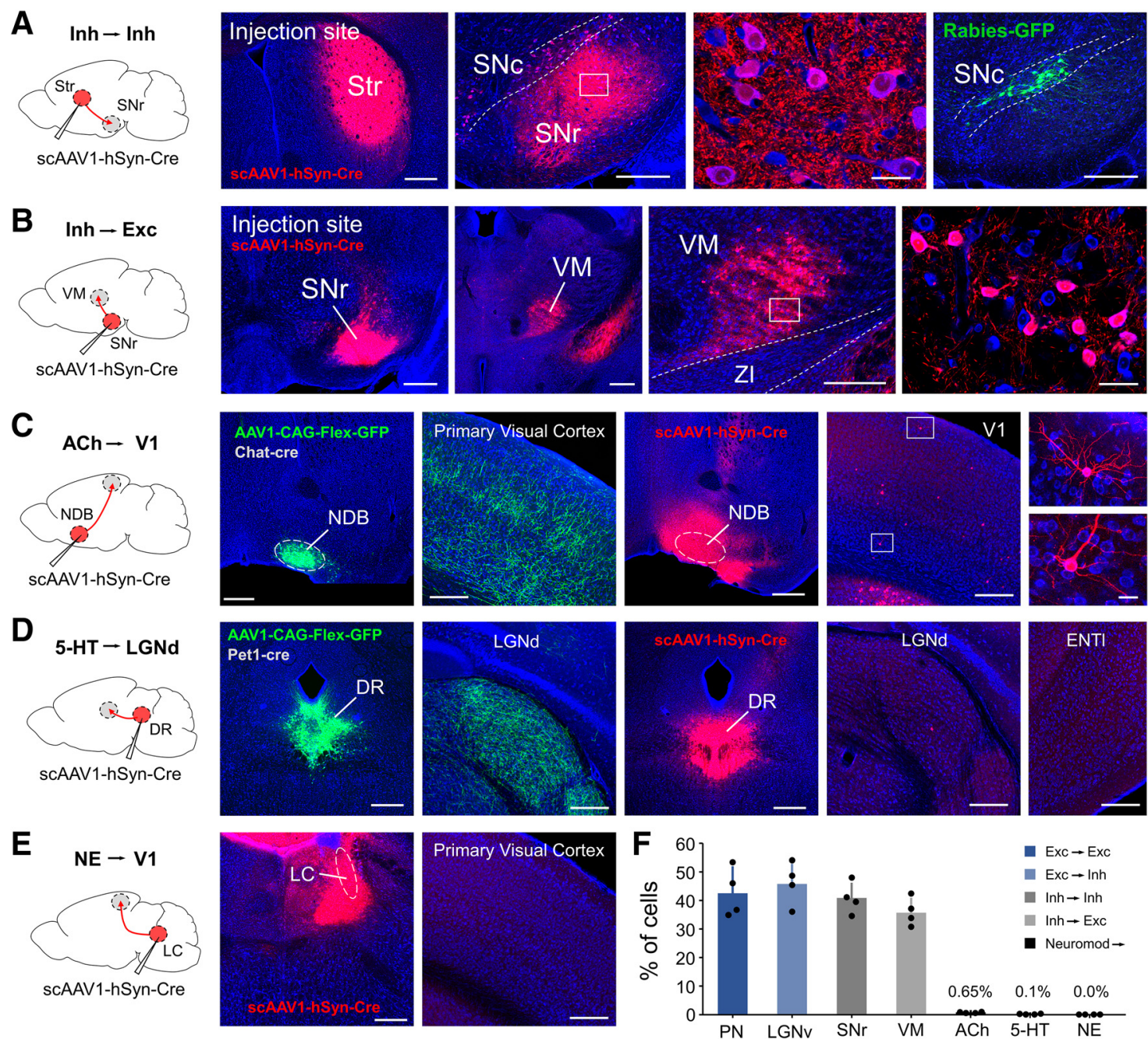

Figure 4. Efficiency of viral spread across different types of synapses. $\boldsymbol{A}$, Anterograde transsynaptic spread of scAAV1-hSyn-Cre in Ai14 mice from inhibitory projection neurons in striatum (left two panels, red; scale bar, $500 \mu \mathrm{m}$ ) to inhibitory neurons in the SNr (middle two; scale bars: $250 \mu \mathrm{m}$, left; $25 \mu \mathrm{m}$, right). Retrograde labeling by Rabies-GFP injection in striatum was restricted primarily to SNc (right, green; scale bar, $250 \mu \mathrm{m}$ ). B. Anterograde transsynaptic spread of scAAV1-hSyn-Cre from inhibitory projection neurons in SNr (left two panels, red; scale bar, $500 \mu \mathrm{m}$ ) to presumed excitatory neurons in VM (right three panels; scale bars: $500 \mu \mathrm{m}$, left; $250 \mu \mathrm{m}$, middle; $25 \mu \mathrm{m}$, right). C, Anterograde transsynaptic spread through cholinergic neurons (left). Cholinergic cells in the NDB project unidirectionally to the primary visual cortex (left second and third panels, green; scale bars: $500 \mu \mathrm{m}$, left; $250 \mu \mathrm{m}$, right). Injection of scAAV1-hSynCre into the NDB sparsely labeled neurons in V1 across different cortical layers (right three panels, red; scale bars: $500 \mu \mathrm{m}$, left; $250 \mu \mathrm{m}$, middle; $25 \mu \mathrm{m}$, right). D, Anterograde transsynaptic spread through serotonergic neurons (left). Serotonergic neurons in DR project unidirectionally to LGNd (left second and third panels, green; scale bars: $500 \mu \mathrm{m}$, left; $250 \mu \mathrm{m}$, right) and ENTI (data not shown). Injection of scAAV1-hSyn-Cre into the DR labeled little or no cells in LGNd or ENTI (right three panels, red; scale bars: $500 \mu \mathrm{m}$, left; $250 \mu \mathrm{m}$, middle; $250 \mu \mathrm{m}$, right). $\boldsymbol{E}$, Anterograde transsynaptic spread through noradrenergic neurons. Injection of scAAV1-hSyn-Cre into the LC (left two panels, red; scale bar, $500 \mu \mathrm{m}$ ). No labeling of cell bodies was observed in downstream regions unidirectionally connected to $L C$, such as V1 (right; scale bar, $250 \mu \mathrm{m}$ ). $\boldsymbol{F}$, Efficiency of transsynaptic spread across different types of synapses (number of tdTomato+ cells/number of Nissl + cells) in each target region shown in $\boldsymbol{A}-\boldsymbol{E}(n=4$ mice each). Data are compared with previous results for excitatory projections from V1 to downstream excitatory (PN) and inhibitory (LGNv) cell types (blue bars). Error bar $=$ SD.

\section{Efficiency of AAV1 spread through inhibitory synapses}

We previously demonstrated that AAV1-Cre can spread from excitatory projection neurons to both excitatory and inhibitory postsynaptic cell types (Zingg et al., 2017). However, whether or not this transport occurs efficiently across other types of synaptic connections in the brain (e.g., through inhibitory or neuromodulatory pathways) remains to be determined. To test this, we first examined the efficiency of anterograde transsynaptic spread from inhibitory neurons to downstream excitatory or inhibitory cell populations in Ai14 mice. To avoid possible retrograde labeling from AAV1 injections (Aschauer et al., 2013; Rothermel et al., 2013; Zingg et al., 2017), only unidirectionally connected regions downstream of each injection site were examined. To characterize the efficiency of spread from inhibitory-to-inhibitory cells, we injected scAAV1-hSyn-Cre into the Str, which contains GABAergic medium spiny neurons that project to inhibitory cells within the $\mathrm{SNr}$ (Fig. $4 A$, left two). Following a 2 week postinjection survival time, numerous tdTomato + cells were found intermingled with dense axon terminals in $\mathrm{SNr}$ (Fig. $4 A$, middle), suggesting the potential for AAV1 to spread through inhibitory synapses to downstream inhibitory neurons. We also observed tdTomato + cells in the overlying SNc (presumed dopaminergic neurons; Fig. $4 A$, third from left), however these were excluded from analysis as they provide strong projections to the Str and may therefore have been retrogradely labeled by AAV1-Cre. This notion is supported by the observation that injections of GFP-expressing G-deleted rabies virus into the same region of the Str robustly back-labeled neurons in $\mathrm{SNc}$, but not in $\mathrm{SNr}$ (Fig. 4A, right). To provide an estimate of the anterograde transsynaptic labeling efficiency from $\mathrm{Str} \rightarrow \mathrm{SNr}$, we quantified the number of tdTomato + neurons relative to the total number of Nissl+ neurons within the boundaries of the axon 
terminal field in $\mathrm{SNr}$ (see Materials and Methods). We found on average $\sim 41 \%$ of the cells within this region were tdTomato + (Fig. 4F, gray), suggesting comparable efficiency to previously reported excitatory projection neuron pathways (Zingg et al., 2017). In addition, using the same approach, we also tested AAV1 spread from inhibitory neurons in the $\mathrm{SNr}$ to presumed excitatory neurons in the VM, another known unidirectional pathway (Fig. 4B). Again, we found relatively efficient anterograde transsynaptic labeling in VM $(\sim 36 \%$ tom $+/$ total Nissl + cells; Fig. $4 F$, light gray), providing further evidence that AAV1 may be used to transsynaptically tag diverse cell populations downstream of different classes of inhibitory projection neurons.

\section{Efficiency of AAV1 spread across neuromodulatory synapses}

To determine if neuromodulatory cell types support anterograde transsynaptic spread of AAV1, we performed similar injections in brain regions that contain cholinergic, serotonergic, or noradrenergic cell populations and examined targets that were exclusively downstream for tdTomato + cell bodies (Fig. 4C-E). Specifically, to reveal transsynaptic spread through cholinergic neurons, we injected the NDB in the anterior basal forebrain, which projects strongly to V1 (Fig. 4C, second and third from left; HuppéGourgues et al., 2018), but does not receive input back from $\mathrm{V} 1$ (Do et al., 2016). Following injections of scAAV1hSyn-Cre into the NDB, we observed sparse tdTomato + neurons scattered throughout all layers of $\mathrm{V} 1$, including layer 1 (Fig. 4C, right three). This suggests AAV1 may have the capacity to spread postsynaptically through cholinergic neurons, albeit much less efficiently than expected given the dense termination pattern in this target structure (Fig. 4C, third from left). Indeed, quantification of the number of tdTomato + cells relative to Nissl + cells within a given $500 \times 500 \mu \mathrm{m}$ region of V1 revealed only $\sim 0.65 \%$ labeling efficiency (Fig. 4F). Similarly, we also observed inefficient spread of AAV1 through serotonergic and noradrenergic cell populations. Serotonergic projections from the DR to the LGNd or ENTl, two exclusively downstream targets (Ogawa et al., 2014; Weissbourd et al., 2014; Prouty et al., 2017), produced almost no transsynaptic labeling (Fig. $4 D$, right three), despite strong axonal innervation of these structures (Fig. 4D, second and third from left). Furthermore, transsynaptic labeling was completely absent in Error bar $=$ SD.
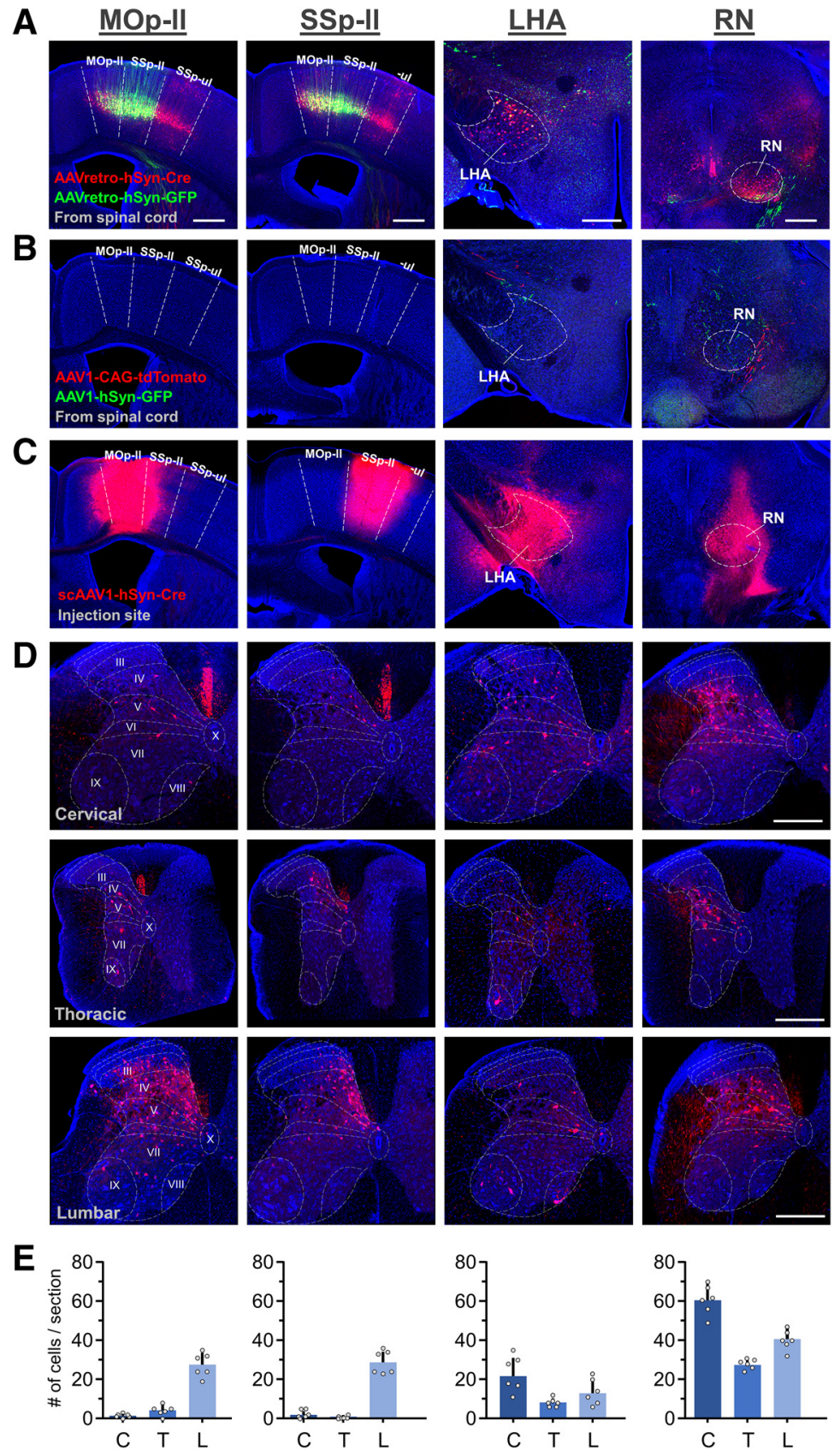

Figure 5. Application in descending pathways to the spinal cord. $\boldsymbol{A}$, Retrograde labeling of spinal-projecting cortical and subcortical neuronal populations following injections of AAVretro-hSyn-Cre (red) and AAVretro-hSyn-GFP (green) into the left side of the cervical and lumbar spinal cord, respectively, in Ai14 mice. Scale bars: $\boldsymbol{A}-\boldsymbol{C}, 500 \mu \mathrm{m}$. $\boldsymbol{B}$, Lack of axonal projections from spinal cord to selected brain regions following cervical injection of AAV1-hSyn-GFP (green) and lumbar injection AAV1CAG-tdTomato (red). C, Corresponding injections of scAAV1-hSyn-Cre (red; $100 \mathrm{nl}$ injection volume) into different spinal-projecting brain regions ( $\boldsymbol{A}$, top) in Ai14 mice. $\boldsymbol{D}$, Different patterns of transsynaptic labeling at cervical, thoracic, and lumbar segments of the spinal cord for each injection following a 2 week postinjection survival time. Each column corresponds to the injection site shown in $\boldsymbol{C}$. Scale bars, $250 \mu \mathrm{m}$. $\boldsymbol{E}$, Quantification of the average number of anterograde transsynaptically labeled cells per coronal section of cervical (C) thoracic (T), or lumbar (L) spinal cord for each injection ( $n=1$ mouse each).

V1 following transduction of noradrenergic neurons in the LC (Fig. 4E), which diffusely project to most cortical areas, including V1 (Polack et al., 2013; Schwarz et al., 2015). Thus, although AAV1 appears to be capable of efficient spread through classically defined glutamatergic and GABAergic synaptic pathways, its application in various neuromodulatory systems may be limited. 
Table 1. List of viruses used in this study

\begin{tabular}{|c|c|c|c|}
\hline$\overline{\text { Virus }}$ & Titer & Source & Addgene Plasmid ID \\
\hline AAV1 hSyn-Cre-WPRE & $2.5 \times 10^{13} \mathrm{GC} / \mathrm{ml}$ & Addgene & 105553 \\
\hline scAAV1 hSyn-Cre & $2.8 \times 10^{13} \mathrm{GC} / \mathrm{ml}$ & Vigene Biosciences & \\
\hline AAV1 hSyn-Flp & $5.5 \times 10^{13} \mathrm{GC} / \mathrm{ml}$ & Vigene Biosciences & 51669 \\
\hline AAV1-CMV-Cre & $2.7 \times 10^{13} \mathrm{GC} / \mathrm{ml}$ & Addgene & 105537 \\
\hline AAV5-CMV-Cre & $2.8 \times 10^{13} \mathrm{GC} / \mathrm{ml}$ & Addgene & 105537 \\
\hline AAV6-CMV-Cre & $3.5 \times 10^{13} \mathrm{GC} / \mathrm{ml}$ & Addgene & 105537 \\
\hline AAVPHP.B-CMV-Cre & $2.3 \times 10^{13} \mathrm{GC} / \mathrm{ml}$ & SignaGen & \\
\hline CAV2-CMV-Cre & $1.3 \times 10^{12} \mathrm{GC} / \mathrm{ml}$ & Montpellier Viral Core & \\
\hline Adenovirus (Ad5-CMV-Cre) & $3.0 \times 10^{12} \mathrm{GC} / \mathrm{ml}$ & Kerafast & \\
\hline Lentivirus (LV-CMV-Cre) & $1.0 \times 10^{8} \mathrm{GC} / \mathrm{ml}$ & Cellomics Tech & \\
\hline Baculovirus (BAC-CMV-Cre) & $3.7 \times 10^{10} \mathrm{GC} / \mathrm{ml}$ & Uni. of lowa & \\
\hline G-deleted Rabies virus (RV-Cre-GFP) & $8.6 \times 10^{8} \mathrm{GC} / \mathrm{ml}$ & Salk Institute & \\
\hline AAVretro-hSyn-GFP-WPRE & $1.7 \times 10^{14} \mathrm{GC} / \mathrm{ml}$ & Vigene Biosciences & 105539 \\
\hline AAV1 hSyn-GFP-WPRE & $3.2 \times 10^{13} \mathrm{GC} / \mathrm{ml}$ & Addgene & 105539 \\
\hline AAV1-EF1a-DI0-hChR2-eYFP-WPRE & $1.6 \times 10^{13} \mathrm{GC} / \mathrm{ml}$ & Addgene & 20298 \\
\hline AAVDJ-CMV-TeNT-P2A-GFP & $5.7 \times 10^{12} \mathrm{GC} / \mathrm{ml}$ & Stanford Viral Core & \\
\hline AAVretro-EF1a-Cre-WPRE & $2.3 \times 10^{13} \mathrm{GC} / \mathrm{ml}$ & Salk Institute & 55636 \\
\hline
\end{tabular}

\section{Transsynaptic categorization of input-defined spinal cord neurons}

We next asked whether AAV1 transsynaptic tagging could be applied in long-range projection pathways from the brain to the spinal cord. To test this, we first identified several brain regions that contained spinal-projecting cell populations by injecting retrogradely transported AAV (AAVretro; Tervo et al., 2016) expressing Cre or GFP in the cervical and lumbar spinal cord, respectively, of Ail4 mice. Based on the retrograde labeling result (Fig. 5A), we selected two cortical regions (MOp-ll and $\mathrm{SSp}-\mathrm{ll}$ ) and two subcortical regions (LHA and RN) for injections of scAAV1-hSyn-Cre, because these regions received no or little input from the spinal cord (Fig. 5B). Following a 2 -week postinjection survival time (Fig. $5 C$ ), robust tdTomato + cell body labeling was observed in the spinal cord for each descending pathway (Fig. 5D), suggesting a capacity for AAV1-Cre to efficiently transduce neurons over long axonal distances. Interestingly, the distribution of this postsynaptic labeling appeared to be regional- and layer-specific for each pathway (Fig. 5D,E), suggesting that different descending projections to the spinal cord recruit unique subpopulations of spinal neurons that may underlie their distinct functional roles. These results further highlight the specificity of anterograde transsynaptic AAV1 spread and reveal its potential use in dissecting the downstream circuit components of different brain-spinal projection pathways.

\section{Comparison between viruses, toxicity, and retrograde transport potential}

Our previous results indicated that AAV1, and to a lesser extent AAV9, are capable of anterograde transsynaptic transport, while other tested serotypes (AAV5, 6, 8) or virus types (CAV2) did not display this property (Zingg et al., 2017). To provide a more comprehensive screen of anterograde transsynaptic transport across a variety of commonly used viruses, we injected equal volumes (60 nl) of adenovirus (Ad5-CMV-Cre), lentivirus (LVCMV-Cre), baculovirus (BAC-CMV-Cre), G-deleted rabies virus
(RV-Cre-GFP), AAVretro-Cre (Tervo et al., 2016), AAV-PHP. B-Cre (Deverman et al., 2016), scAAV1-hSyn-Cre, or AAV1hSyn-Flp into V1 of Ail4 mice (for Cre-expressing viruses) or GFP-expressing Flp-reporter mice (Frt-GFP, for AAV1-hSynFlp; Table 1). Animals were euthanized 4 weeks following injection and the number of postsynaptically labeled cells in SC was quantified for each virus injection and plotted alongside previously reported data for additional viruses (Fig. 6D; Zingg et al., 2017). Besides AAV1 (and to a lesser extent AAV9), none of the tested viruses yielded any anterograde transsynaptic labeling in SC (Fig. 6D), suggesting that AAV1 is unique in its capacity to efficiently spread to neurons downstream of an injection site. In addition, we observed that AAV1-hSyn-Flp was capable of labeling comparable numbers of cells in SC compared with Creexpressing AAV1 constructs (Fig. 6C,D), suggesting this approach may be applied interchangeably with AAV1 viruses expressing different forms of recombinase.

Moreover, among the four AAV1 viruses tested, we observed a nearly twofold increase in the number of anterograde transsynaptically labeled cells when using AAV1-hSyn-Cre-WPRE compared with scAAV1-hSyn-Cre, AAV1-CMV-Cre, or AAV1hSyn-Flp, which each lack the WPRE (Fig. 6D; Table 1). This enhancer element can stabilize mRNA transcripts and increase the expression of AAV gene products by sevenfold (Loeb et al., 1999), however overexpression of Cre recombinase may become toxic to host cells at the injection site, as evident in Figure 6A (middle; Haery et al., 2019). To avoid this complication, all experiments in this study used scAAV1-hSyn-Cre and AAV1hSyn-Flp, which do not exhibit any signs of toxicity at the injection site and still yield large numbers of transsynaptically labeled cells (Fig. 6A-C).

Finally, in addition to anterograde transsynaptic spread, we previously observed that AAV1-Cre has the capacity to be retrogradely transported to neurons presynaptic to the injection site, thus limiting its use to unidirectional, rather than reciprocally connected pathways (Zingg et al., 2017; Rothermel et al., 2013). To better characterize the efficiency of each of these transport 


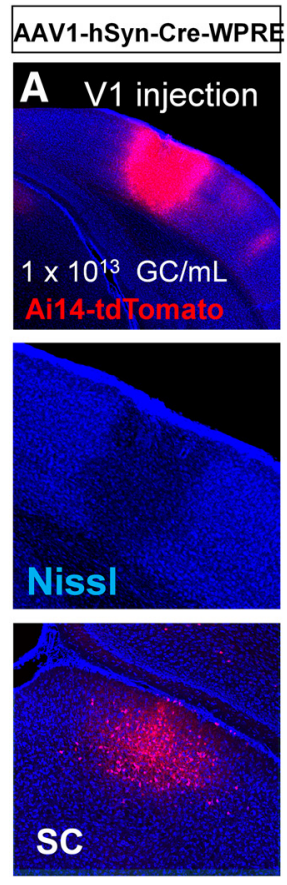

D

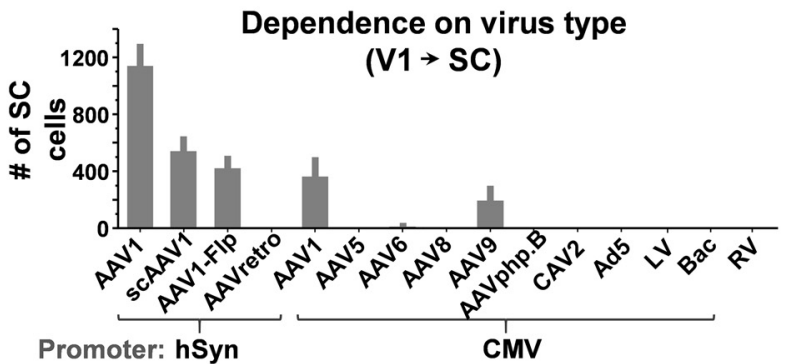

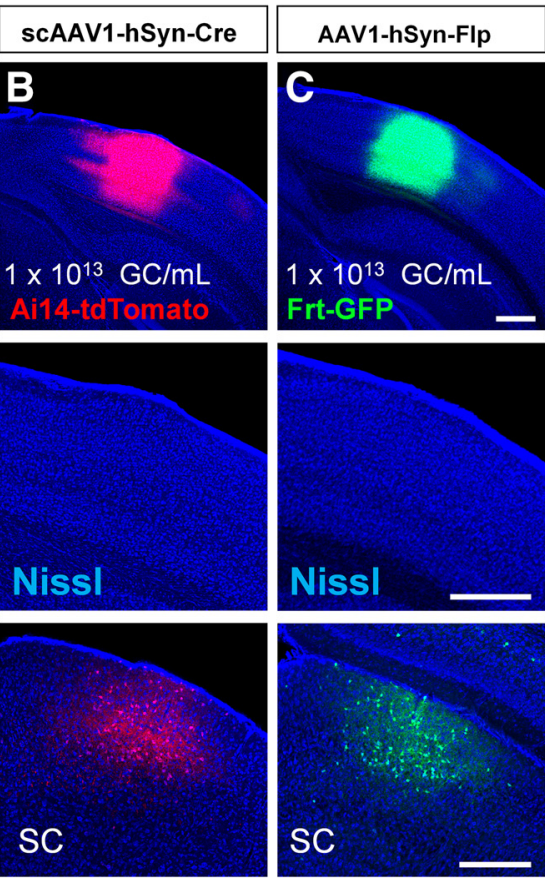

CMV
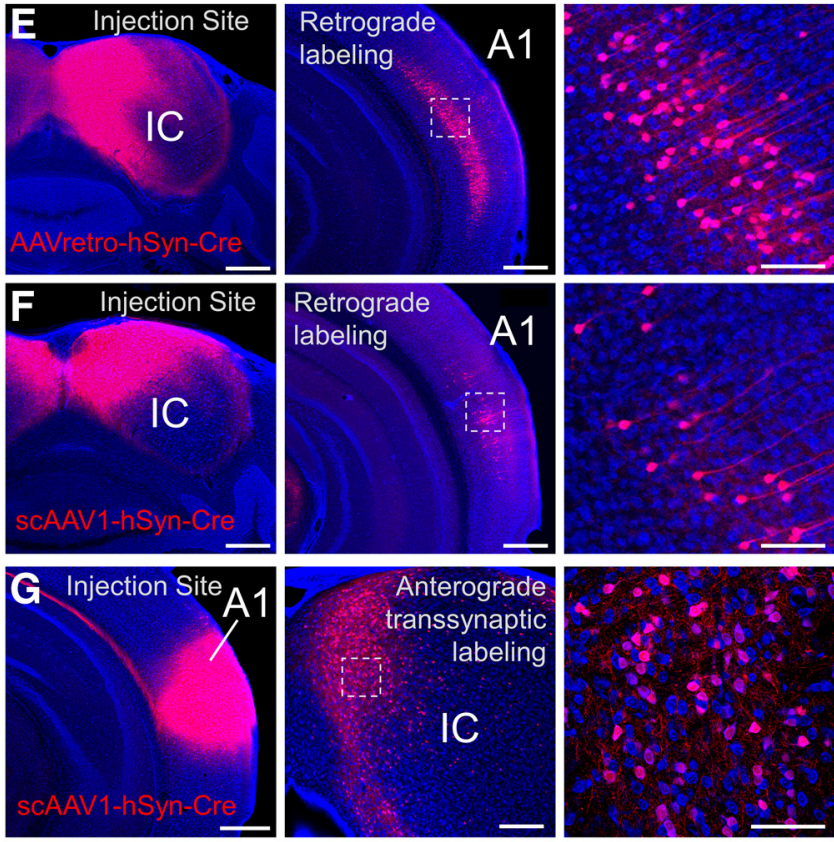

H

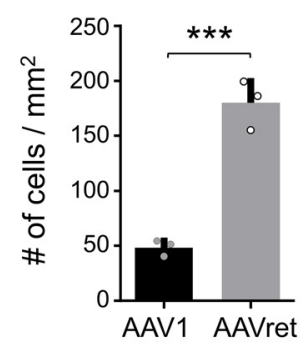

I

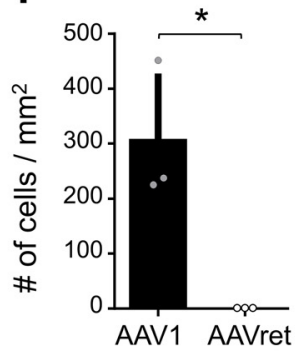

Figure 6. Comparison of anterograde transsynaptic spread, toxicity, and retrograde transport potential. A, Injection of AAV1-hSyn-Cre-WPRE in V1 of Ai14 mice (top). Overexpression of (re may result in cell death at the injection site, as seen by a reduction in Nissl stain intensity and irregular cell morphology (middle). Bottom, Anterograde transsynaptically labeled neurons in SC. B, Injection of scAAV1-hSyn-Cre in Ai14 mice (top). This virus lacks the WPRE enhancer and shows no apparent toxicity in neurons at the injection site (middle). Bottom, Anterograde transsynaptically labeled neurons in SC. C, AAV1-hSyn-Flp injection in Frt-GFP mice (top). This virus also lacks the WPRE enhancer and shows no apparent toxicity (middle). Bottom, Anterograde transsynaptically labeled neurons in SC. All injections $60 \mathrm{nl}$ total volume, 4 week postinjection survival time. Scale bars, $500 \mu \mathrm{m}$. D, Quantification of total number of cells labeled in SC for different Cre or Flp-expressing viruses injected into V1 (4 week postinjection survival, $60 \mathrm{nl}$ injection, $n=4$ mice each). Error bar $=$ SD. $\boldsymbol{E}$, Injection of AAVretro-hSyn-Cre in IC of Ai14 mice (left). Retrograde labeling in A1 (middle), and close-up of dashed region (right). Scale bars: left and middle, $500 \mu \mathrm{m}$; right, $100 \mu \mathrm{m}$. $\boldsymbol{F}$, Injection of scAAV1-hSyn-Cre in IC of Ai14 mice (left). Retrograde labeling in A1 (middle), and close-up of dashed region (right). Scale bars: left and middle, $500 \mu \mathrm{m}$; right, $100 \mu \mathrm{m}$. G, Injection of scAAV1-hSyn-Cre in A1 of Ai14 mice (left). Anterograde transsynaptic labeling of cells in IC (middle), and close up of dashed region (right). Scale bars: left and middle, $500 \mu \mathrm{m}$; right, $100 \mu \mathrm{m}$. $\boldsymbol{H}$, Quantification of retrograde labeling in A1 following injection of scAAV1-hSyn-Cre or AAVretro-hSyn-Cre in IC ( $n=3$ mice for each group). All injections $80 \mathrm{nl}$ total volume, 2 week postinjection survival time. Error bar $=$ SD. ${ }^{* * *} p<0.001, t$ test. $I$, Quantification of anterograde transsynaptic labeling in IC following injection of scAAV1-hSyn-Cre or AAVretro-hSyn-Cre in A1 ( $n=3$ mice for each group). All injections $80 \mathrm{nl}$ total volume, 2 week postinjection survival time. Error bar $=S D .{ }^{*} p<0.05, t$ test.

properties, we examined the retrograde and anterograde transsynaptic spread of AAV1 within the same pathway (Fig. $6 E-I$ ), and compared it with that of a well characterized retrograde variant of AAV (AAVretro-hSyn-Cre; Tervo et al., 2016). Following injection into A1 or IC with either scAAV1-hSyn-Cre or AAVretro-hSyn-Cre at equivalent titer $(2.8 \times 1013 \mathrm{GC} / \mathrm{ml}, 80 \mathrm{nl}$ total volume) in Ail4 mice, animals were euthanized (2 week postinjection survival time) and the number of retrogradely labeled tdTomato + cells in A1 or anterograde transsynaptically labeled cells in IC were quantified (Fig. 6H,I). The density of retrograde labeling in A1 was $\sim$ four times greater for AAVretroCre compared with scAAV1-Cre (average of 180 cells $/ \mathrm{mm}^{2}$ compared with 48 cells $/ \mathrm{mm}^{2}$, respectively; Fig. $6 H$ ) and a broader labeling pattern across A1 was observed for AAVretro-Cre, indicating greater retrograde transport efficiency than scAAV1-Cre (Fig. 6E,F, middle). Alternatively, as expected, a large number of anterograde transsynaptically labeled neurons was observed in
IC following injection of scAAV1-Cre, but not AAVretro-Cre, in IC (Fig. 6G,I; average of 310 cells $/ \mathrm{mm}^{2}$ compared with 0 cells/ $\mathrm{mm}^{2}$, respectively). Overall, however, given the significant capacity for AAV1 to be transported retrogradely, as indicated in Figure $6 \mathrm{~F}$ and $H$, caution must be taken to apply AAV1 anterograde transsynaptic mapping only in well-established, unidirectionally connected pathways.

\section{Dual anterograde transsynaptic tagging of topographically} defined cell populations

As corticofugal output represents one of the largest and most straight-forward systems for applying anterograde transsynaptic tagging, we aimed to explore in greater detail its potential for accessing input-defined cell populations throughout the entire brain. In particular, given the highly topographical nature of corticofugal output, we asked whether AAV1-Cre and AAV1-Flp 


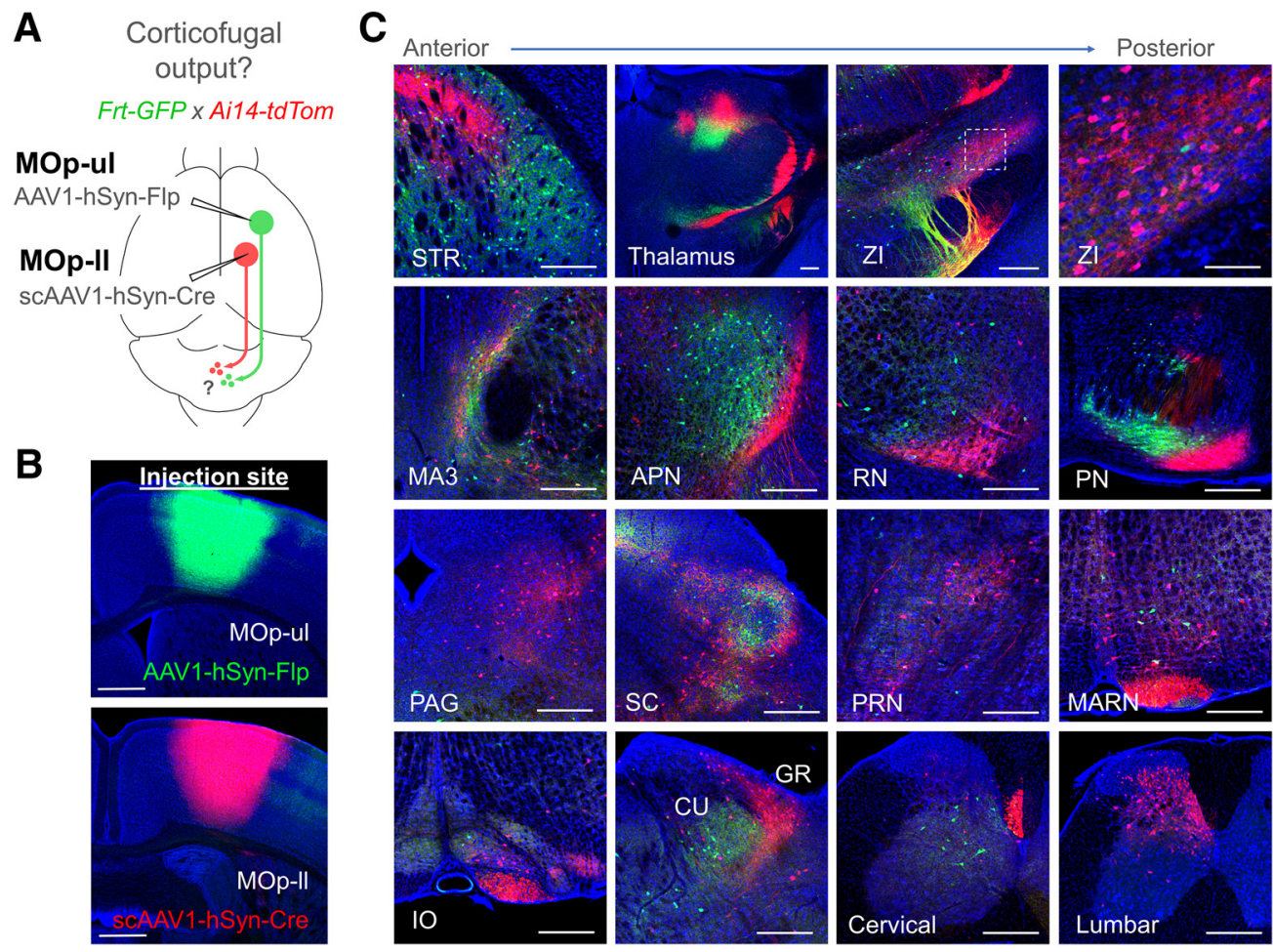

Figure 7. Accessing topographically precise, input-defined cell populations through corticofugal pathways. $\boldsymbol{A}$, Strategy for labeling cell populations that receive input from upper limb(green) and lower limb- (red) related primary motor cortex in Ai14 x Frt-GFP (Cre and Flp reporter) mice. B, Injection sites for AAV1-hSyn-Flp in MOp-ul (top, green) and scAAV1-hSyn-Cre in MOp-II (bottom, red) in an Ai14 x Frt-GFP mouse. Scale bar, $500 \mu \mathrm{m}$. C, Anterograde transsynaptic labeling of cells that receive input from upper limb- (green) or lower limb- (red) related primary motor cortex. Many closely apposed, non-overlapping cell populations were observed in mid- and hindbrain structures, including the PN (second row, right). None of the structures shown project back to motor cortex, with the exception of the thalamus (top row, third from left), which may contain both retrograde and anterograde transsynaptic labeling of cell bodies. Scale bars, $250 \mu \mathrm{m}$. GR, Gracile nucleus; MA3, medial accessory oculomotor nucleus; MARN, magnocellular reticular nucleus; PRN, pontine reticular nucleus.

could be used together to simultaneously reveal the topographic distribution of cells innervated by two functionally distinct cortical regions. To test this, we injected AAV1-hSyn-Flp in the upper-limb-related primary motor cortex (MOp-ul) and scAAV1-hSyn-Cre into MOp-ll in a Flp- and Cre-reporter mouse (Frt-GFP x Ai14-tdTomato; Fig. 7A,B). After 2 weeks, we then examined all subcortical targets for the presence of GFP+I $\mathrm{Flp}+$ or tdTomato $+/ \mathrm{Cre}+$ cell bodies corresponding to output from either MOp-ul or MOp-ll, respectively. The thalamus was excluded from analysis due to its reciprocal connectivity with each injection site, however topography was still evident in this structure (Fig. 7C, top row, second from left). Remarkably, several brain regions, including the Str, zona incerta (ZI), medial accessory oculomotor nucleus (MA3), anterior pretectal nucleus (APN), RN, PN, and SC, contained discrete, nonoverlapping populations of GFP + or tdTomato + cells that subdivided each structure based on its input from upper- or lower-limb-related motor cortex (Fig. 7C). In addition, we also observed structures such as caudal PAG, pontine reticular nucleus, and cuneate and gracile nuclei, which were preferentially labeled by one pathway, but not the other (Fig. 7C, bottom two rows).

Given this potential to subdivide certain structures based on their topographic input (Fig. 8A), we next asked whether PN neurons defined by their unidirectional input from MOp-ul or MOp-ll might in turn project to upper- or lower-limb-related portions of the cerebellum, thus bridging two somatotopically organized systems and providing some cross-validation for the specificity of these transsynaptically tagged subpopulations (Brodal and Bjaalie, 1992; Kratochwil et al., 2017). To test this idea, we injected scAAV1-hSyn-Cre into MOp-ul or MOp-ll and
AAV1-CAG-Flex-GFP into the PN to Cre-dependently express GFP in each subpopulation of input-defined PN neurons (Fig. $8 B, D)$. We then examined the cerebellum for GFP + axon terminals in each case. Interestingly, we found that MOp-ul-recipient PN neurons projected primarily to the contralateral PRM lobule, which has been shown to respond to forelimb stimulation in micromapping studies (Shambes et al., 1978; Odeh et al., 2005) and has been shown to receive di-synaptic input specifically from the forelimb motor cortex via the PN using multisynaptic rabies virus tracing (Suzuki et al., 2012; Fig. 8C). On the other hand, MOp-ll-recipient PN neurons projected strongly to the COP lobule of the cerebellum, but avoided the PRM (Fig. 8E), as expected based on previous functional and anatomic mapping studies (Atkins and Apps, 1997; Voogd et al., 2003; Odeh et al., 2005; Suzuki et al., 2012; Fig. 8F,G). Together, these results provide evidence that AAV1-transsynaptic tagging may be broadly applied in various corticofugal pathways to experimentally access, map, and manipulate specific subpopulations of neurons defined by their topographic cortical input.

\section{Application in sparse labeling approaches for single neuron reconstruction}

To better characterize populations of neurons that receive input from a given pathway, it may be useful to recover their individual morphologic and axonal targeting features. Given the normally dense arrangement of these processes, this is greatly facilitated by using a method to sparsely label only a small number of cells at a time. To achieve sparse labeling in a given Cre-expressing cell population, we reasoned that coinjections of a low titer Cre-dependent Flp-expressing virus (AAV1-DIO-Flp) and a high titer 
A
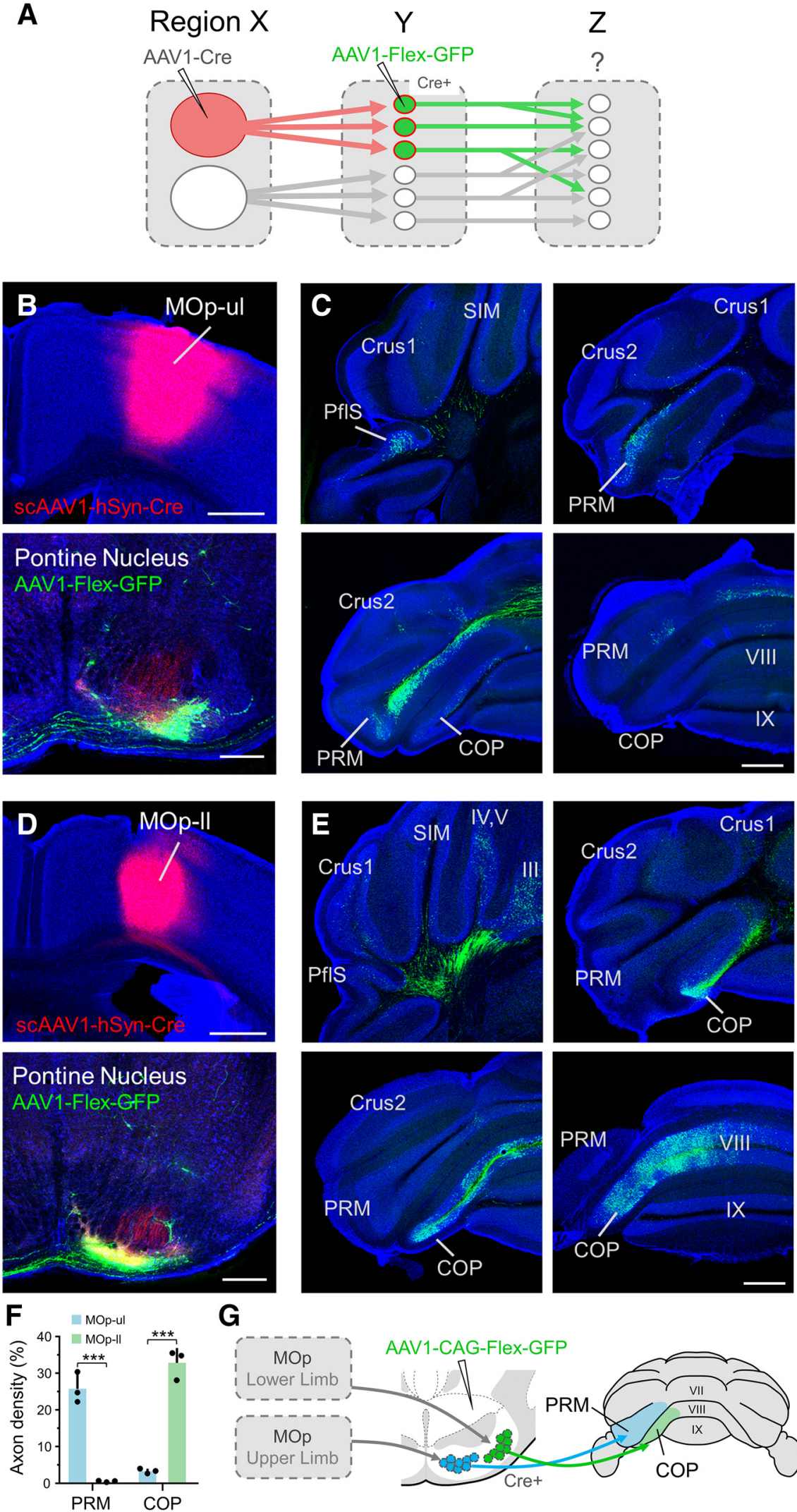

G

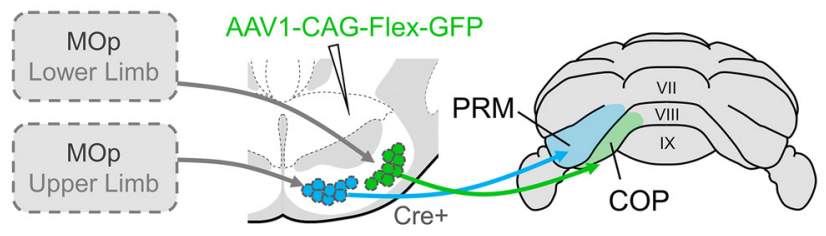

Figure 8. Forward mapping of topographically organized brain regions. A, Schematic diagram depicting the parcellation of brain regions (in $\eta$ ) based on their topographical input (from $X$ ) using an anterograde transsynaptic approach. Secondary injections of AAV1-Flex-GFP enable further mapping of axonal outputs (to Z) for any given input-defined subregion. A retrograde approach may not provide access to the same population because of collateralization of divergent outputs. $\boldsymbol{B}$, Top, tdTomato expression at the injection site, M0p-ul, following first injection of scAAV1-hSyn-Cre. Bottom, Cre+/GFP+ neurons are shown in PN following secondary injection of AAV1-hSyn-Flex-GFP in PN. Scale bar, $250 \mu$ m. C, Axonal projections to the cerebellum from PN neurons defined by their input from MOp-ul. Axons primarily target the contralateral parafloccular sulcus (PfIS; top left) and the ventral PRM. Scale bar, $500 \mu \mathrm{m}$. D, Top, first injection in MOp-II. Bottom, Cre+/GFP+ neurons in PN following secondary injection of AAV1-hSyn-Flex-GFP in PN. Scale bar, $250 \mu \mathrm{m}$. $\boldsymbol{E}$, Axonal targeting in CB. Output was primarily restricted to the 
Flp-dependent YFP-expressing virus $\left(\mathrm{AAV}_{\mathrm{DJ}}\right.$-fDIO-YFP) could be used to obtain robust levels of YFP expression in only a few cells (Fig. 9A), similar to a recent study (Lin et al., 2018). To establish a relationship between titer and the resulting number of labeled cells, AAV1-DIO-Flp was diluted to a final concentration of either $7.5 \times 108,10^{9}$, or $10^{10} \mathrm{GC} / \mathrm{ml}$ and coinjected with $\mathrm{AAV}_{\mathrm{DJ}^{-}}$fDIO-YFP $(1.2 \times 1013 \mathrm{GC} / \mathrm{ml}, 50 \mathrm{nl}$ total volume $)$ in $\mathrm{V} 1$ of Ai14 x PV-Cre mice, which express Cre in PV+ cortical interneurons (Fig. 9B). At this injection volume, we found that titers around $7.5 \times 109 \mathrm{GC} / \mathrm{ml}$ consistently labeled $\sim$ four $\mathrm{PV}+$ cells per animal, enabling recovery of cell morphology (Fig. 9C), whereas titers $\sim 7.5 \times 108 \mathrm{GC} / \mathrm{ml}$ labeled only one cell in one out of four animals (Fig. 9B,D). Therefore, working around a concentration of $10^{9} \mathrm{GC} / \mathrm{ml}$ and adjusting for the relative difference in starter population density, it may be possible to apply this approach to any given group of Cre-expressing neurons, including those labeled using anterograde transsynaptic spread of AAV1-Cre.

Transsynaptic tagging may be applied in different Creexpressing transgenic mice to access both input- and geneticallydefined cell types in a given downstream circuit (Zingg et al., 2017). We therefore explored an additional means to achieve sparse labeling in cell populations that meet these criteria. As a test system, we examined the projection from the ACA to the PAGdl, which is unidirectional (Vianna and Brandão, 2003). Following injections of scAAV1-hSyn-Cre in the ACA of Ai14 x GAD67-GFP mice (Fig. 9E, top), a mixture of transsynaptically labeled GABAergic (GFP+/tdTomato + ) and presumed glutamatergic (GFP-/tdTomato + ) neurons were observed primarily within the PAGdl (Fig. 9E, bottom), suggesting descending projections from ACA may innervate both cell types. To select only glutamatergic neurons for analysis, similar injections may be performed in ACA of Vglut2-Cre mice using AAV1-DIO-Flp and a secondary injection of $\mathrm{AAV}_{\mathrm{DJ}}$ - $\mathrm{fDIO}-\mathrm{YFP}$ within the PAGdl to label input-defined glutamatergic Cre $+/ \mathrm{Flp}+$ cells with YFP. With high titer AAV1-DIO-Flp (e.g., $>10^{13} \mathrm{GC} / \mathrm{ml}$ ) and $\mathrm{AAV}_{\mathrm{DJ}}-\mathrm{fDIO}-\mathrm{YFP}$, these injections are expected to label a large number of cells in PAGdl. However, AAV1-DIO-Flp may be diluted to achieve less transsynaptic labeling, as we previously demonstrated that efficiency of spread is titer dependent (Zingg et al., 2017). In particular, previous results revealed that reducing viral titer from $\sim 10^{13} \mathrm{GC} / \mathrm{ml}$ to $\sim 10^{12} \mathrm{GC} / \mathrm{ml}$ reduces transsynaptic labeling efficiency by $\sim 85-90 \%$. As our test injection of scAAV1-hSyn-Cre at $10^{13}$ titer yielded an average of 35 GFP-/ tdTomato + cells (presumed glutamatergic neurons) per 300 $\mu \mathrm{m}^{3}$ sample space of PAGdl, we expected that similar injections of AAV1-DIO-Flp at $10^{12}$ titer would tag $\sim 4$ Vglut2-Cre +/Flp + within the same sample region (see Materials and Methods for details). This sparse population could then be targeted for robust YFP expression following local injection of high titer $\mathrm{AAV}_{\mathrm{DJ}^{-}}$ fDIO-YFP (Fig. 9F). Following this protocol, we were able to label a single input-defined glutamatergic neuron in PAGdl (Fig. $9 G, H)$. Combined with methods for tissue clearing and whole-

\section{$\leftarrow$}

(COP (top right and bottom), but also collateralize more sparsely to lobules III, IV, and V (top left). Scale bars, $500 \mu \mathrm{m}$. $\boldsymbol{F}$, Quantification of the density of axon terminals in PRM or COP for PN neurons defined by their input from MOp-ul (blue) or MOp-II (green; $n=3$ mice for each group). Values represent the fraction of fluorescent axon signal divided by the total area of the target lobule. Error bar $=S D .{ }^{* *} p<0.001, t$ test. G, Schematic summary of axonal projections to cerebellum from MOp-ul and MOp-II-recipient PN neurons (green and blue, respectively). Posterior view of the cerebellum is shown. brain imaging, it may be possible to systematically reconstruct both local morphology and all long-range axonal projections for any given sparsely labeled group of input- and geneticallydefined cells.

\section{Discussion}

In this study, we provide a systematic characterization of the synaptic specificity of AAV1 transneuronal spread and examine its transport efficiency throughout a diverse set of neural pathways. Overall, we find the virus to be highly selective in its transduction of postsynaptic neurons and broadly applicable in all pathways tested, with the exception of several neuromodulatory cell types (i.e., serotonergic, cholinergic, and noradrenergic neurons). In addition, we reaffirm the observation that anterograde transsynaptic spread is unique to AAV1 (and to some extent AAV9), following an expanded comparison with additional AAV serotypes and other common neurotropic viruses (Fig. 6D). As expected, transsynaptic spread is not specific to Cre-expressing AAV1, per se, as shown by Flp-expressing virus (AAV1-hSynFlp) in a Flp-reporter mouse (Frt-GFP; Sousa et al., 2009). Thus, AAV1-mediated transsynaptic tagging may be expanded to include a variety of recombinase systems to facilitate intersectional approaches for accessing cell types based on multiple criteria.

\section{Transsynaptic spread of AAV1}

We intended to address the synaptic specificity of AAV1 spread from anatomic, functional and molecular aspects. To anatomically test the synaptic specificity of AAV1 spread, we examined its capacity to exclusively label cell types known to be innervated by either pontine or inferior olive afferents to the cerebellum (Palay and Chan-Palay, 1974; Kanichay and Silver, 2008; Mathews et al., 2012). Focusing on downstream Purkinje and GCs, AAV1 transport through each of these pathways demonstrated a high degree of synaptic specificity, largely labeling either the expected GC population but not PCs (PN pathway), or PCs but not GCs (IO pathway). The observed labeling patterns were not entirely perfect, however, as indicated by the presence of small numbers unexpected Purkinje or GCs for each respective pathway, and we estimated that $\sim 1-4 \%$ of the downstream population may be attributed to leaky viral spread for a given pathway.

In addition, we observed labeling of other cell types in the $\mathrm{CB}$ following injections in either PN or IO. In particular, PN injections labeled large GAD67-GFP+ neurons in the granule layer (presumed Golgi cells), which are known to receive synaptic input from PN mossy fiber afferents (Kanichay and Silver, 2008), and we observed MLI and presumed Golgi cell labeling following injections into the IO. In the latter case, these two cell types have been shown to be functionally coupled to olivary afferents through non-classical synaptic connections (Schulman and Bloom, 1981; Szapiro and Barbour, 2007; Xu and Edgley, 2008; Coddington et al., 2013; Nietz et al., 2017). For example, in slice recording experiments, Nietz et al. (2017) observed short-latency EPSCs in Golgi neurons following optogenetic activation of olivary axon terminals. However, they further characterize this signaling to be mediated by glutamate spillover, rather than classical synaptic transmission, based on the response kinetics and sensitivity to glutamate transporter blockade. In this case, close apposition of transmitter release sites and Golgi cell dendrites permits short-latency functional responses, and may therefore allow AAV1 release and transduction of Golgi cells along a similar path. 


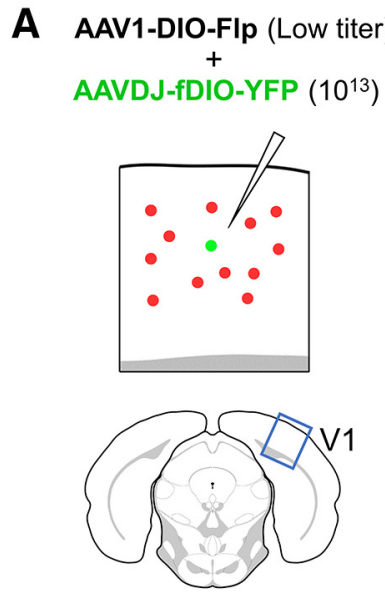

PV-Cre $x$ Ai14
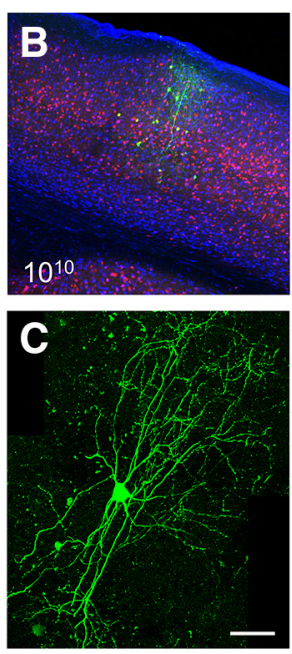
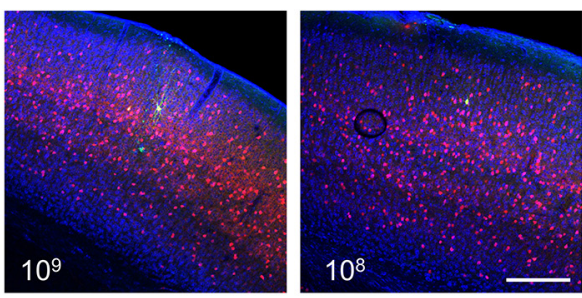

D

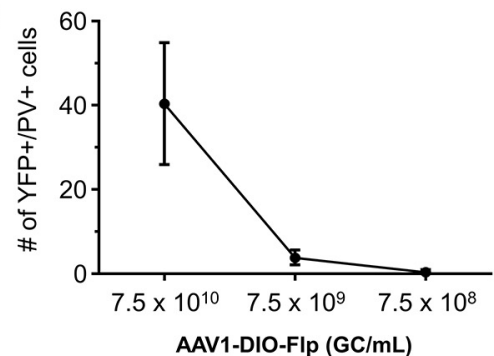

$E$

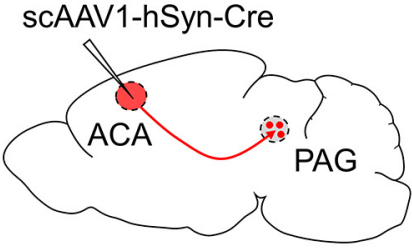

GAD67-GFP x Ai14
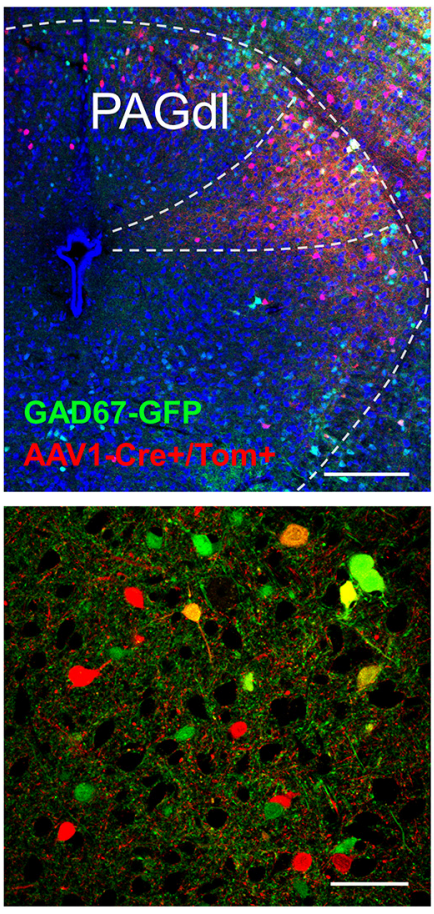

F $\quad$ AAV1-DIO-FIp

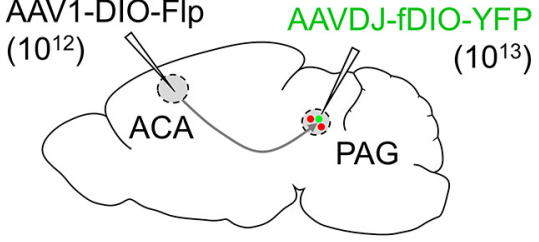

Vglut2-Cre $x$ Ai14
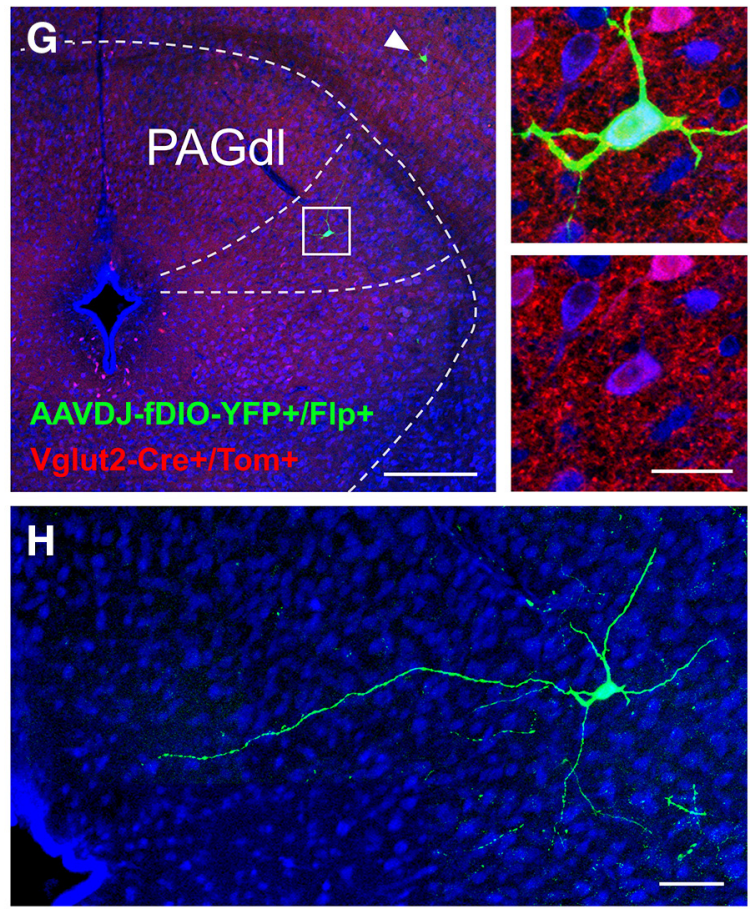

Figure 9. Application with sparse labeling approaches for reconstructing single neuron morphology. $\boldsymbol{A}$, For a given (re + cell population (red), sparse labeling (green) may be achieved by

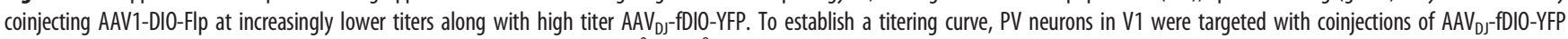
(final titer: $1.2 \times 1013 \mathrm{GC} / \mathrm{ml}$ ) and AAV1-DI0-Flp (final titers: $7.5 \times 1010,10^{9}$, or $10^{8} \mathrm{GC} / \mathrm{ml}$ ) in PV-Cre x Ai14 mice. B, Examples of YFP cell labeling (green) achieved at each titer step. Red, PV-Cre+/tdTomato + cells. Blue, Fluorescent Nissl. Scale bar, $250 \mu \mathrm{m}$. C, 40× magnification of a YFP+ PV neuron labeled in (B, middle). Scale bar, $25 \mu \mathrm{m}$. $\boldsymbol{D}$, Quantification of the number of YFP + /PV + cells labeled at each titer step ( $n=4$ mice each). Error bar $=$ SD. $E$, Injection of scAAV1-hSyn-Cre in the ACA of GAD67-GFP x Ai14 mice transsynaptically labels neurons in PAG. Labeled cell density is greatest in the PAGdl (middle), and both inhibitory (GFP+/tdTomato+) and presumed excitatory (GFP-/tdTomato+) cell types are labeled (bottom; $40 \times$ magnification). Scale bars: middle, $250 \mu \mathrm{m}$; bottom, $50 \mu \mathrm{m}$. $\boldsymbol{F}$, Strategy for sparse labeling of input- and genetically-defined cell populations. AAV1-DI0-Flp titer for injection in ACA is reduced to $1.5 \times 1012 \mathrm{GC} / \mathrm{ml}$ to achieve sparse anterograde transsynaptic labeling in PAGdl. Individual Vglut2-Cre +/Flp + neurons may then be targeted with an injection of high titer AAVD-fDIO-YFP to specifically label glutamatergic neurons in PAGdl that receive input from ACA. G) Example of a single Vglut2-(re+/Flp + neuron labeled in PAGdl (green). An additional neuron was found in the superior colliculus (arrowhead). Right, 40× magnification of YFP+ (green, top) and Vglut2-Cre+/Tom + (red, bottom) neuron in PAGdl. Blue, Fluorescent Nissl. Scale bars: left, $250 \mu \mathrm{m}$; right, $25 \mu \mathrm{m} . \boldsymbol{H}, 40 \times$ magnification of local dendrites and axonal projection of the YFP+ PAGdl neuron shown in $\boldsymbol{G}$. Scale bar, $50 \mu \mathrm{m}$. 
To functionally examine the transsynaptic spread of AAV1, we recorded from both labeled and neighboring nonlabeled neurons in the target region to establish a statistical association between labeling and presynaptic connectivity, and between nonlabeled neurons and a lack of presynaptic connectivity. We found that all of the labeled neurons we recorded from were monosynaptically connected to the presynaptic starting population, whereas only $\sim 46 \%$ of neighboring non-labeled cells exhibited presynaptic input. A caveat to this experimental design is that ChR2 may be expressed in a greater number of upstream neurons than the actual number responsible for transsynaptic transport of AAV1-Cre. In addition, ChR2-labeled axons may collateralize extensively in the target region, whereas AAV1-Cre does not spread with $100 \%$ efficiency to label every possible postsynaptic neuron. This would result in some unlabeled neurons exhibiting a synaptic response, and the potential for overestimating true synaptic connectivity in labeled neurons. The ideal experiment would be to test the spread of AAV1-Cre through a single ChR2-labeled neuron to establish a one-to-one correlation between the source of light-activated axonal input and the postsynaptically labeled cell population. Unfortunately, such an experiment is technically not feasible at this point in time. Nonetheless, our recording results reveal a statistically significant association between postsynaptic AAV spread and presynaptic connectivity, suggesting AAV1 may favor a synaptic mechanism of transport.

Last, the dependence of transsynaptic spread on synaptic vesicle release, as demonstrated by impairment of viral spread by TeNT expression in starting cells, suggests a predominately presynaptic mechanism of viral release. Given this potential reliance on synaptic vesicle fusion for viral release, it would be interesting to know whether neural activity is required for viral spread or if it is more efficient in cells that exhibit higher firing rates or are tonically active. Furthermore, as transsynaptic spread of AAV1 was not completely blocked by TeNT expression, the possibility remains that other vesicle release mechanisms that do not require VAMP2, such as fusion of multivesicular bodies, can contribute modestly to transneuronal spread (Von Bartheld and Altick, 2011; Raposo and Stoorvogel, 2013; Janas et al., 2016; Hessvik and Llorente, 2018). These may release their contents extrasynaptically, or into the synaptic cleft following fusion with the presynaptic membrane in regions adjacent to active zones for synaptic vesicle docking (Janas et al., 2016).

Together, our results collectively provide deeper insight into the synaptic nature of AAV1 transneuronal spread and suggest that transport through transsynaptic mechanisms contributes to the majority of the observed labeling in each of the pathways examined here.

\section{Efficiency of transsynaptic spread through diverse brain pathways}

Previously, we characterized the transsynaptic spread of AAV1 through glutamatergic projection pathways (e.g., corticofugal, retino-collicular, colliculo-thalamic). Here we provide a more systematic characterization of AAV1 spread through pathways using different types of synapses (e.g., inhibitory or neuromodulatory) or projecting over long axonal distances (e.g., cortex to spinal cord). Our results indicate that AAV1 is capable of transducing both excitatory and inhibitory cell types downstream of GABAergic projection pathways ( $\mathrm{Str} \rightarrow \mathrm{SNr}$, and $\mathrm{SNr} \rightarrow \mathrm{VM}$ ) with efficiencies comparable to previously reported glutamatergic pathways (Fig. 4F). In addition, AAV1 transport through long-range spinal-projecting populations yielded robust and regionally-specific labeling patterns in the spinal cord for each unidirectional pathway tested, suggesting that transport efficiency is not compromised by axon length. On the other hand, injections in three different neuromodulatory cell populations (cholinergic, serotonergic, and noradrenergic) failed to yield efficient transsynaptic labeling in their respective unidirectional downstream targets. Several factors may account for this lack of efficiency, including differential expression of extracellular receptors needed for AAV1 uptake, differences in viral trafficking to axon terminals, and/or "volume" release of viral particles into the extracellular space via axonal varicosities rather than through classical synaptic contacts, which may reduce the probability of uptake by downstream neurons (Agnati et al., 1995; Arroyo et al., 2014). Overall, our results suggest that AAV1 is capable of efficient transsynaptic transport through a wide variety of excitatory and inhibitory projection pathways.

\section{Application and future directions}

In its current form, anterograde transsynaptic spread of any recombinase-expressing AAV1 may be used to gain experimental access to downstream cell populations that might otherwise be difficult to target due to their small size, laminar organization (e.g., ZI), and/or lack of identified genetic markers and corresponding transgenic mice. Given the non-toxic nature of AAV, these populations may then be targeted for long-term expression of genetically encoded tools for mapping their connectivity and probing their functional role. In addition, our results highlight the value of applying an anterograde transsynaptic approach, rather than a genetic or retrograde viral approach, in subdividing topographically organized brain regions based on their input. These regions, such as the striatum or PN, contain relatively homogeneous distributions of cell types, however discrete populations within these structures may process different types of information based on the source of their cortical input (e.g., from upper-limb or lower-limb related motor cortex). In turn, each population may have topographically unique output, as demonstrated in the cerebellar targeting of two input-defined subregions of PN (Fig. 8F). Accessing these same populations using a retrograde viral approach, however, may not be feasible given the potential for divergent collateralization of their output (Fig. $8 \mathrm{~A}$ ), and genetically specifying such input-defined populations may not be possible given the homogeneity of cell types within the structure. Last, we demonstrate that AAV1 transsynaptic tagging may be used to catalog cell types based on their input, morphology, and gene expression by incorporating the use of transgenic mice and techniques for achieving sparse labeling of transsynaptically tagged neurons (Kim et al., 2017; Gouwens et al., 2019; Li et al., 2019; Winnubst et al., 2019).

Given that AAV1 is also capable of retrograde transport (Aschauer et al., 2013; Rothermel et al., 2013; Masamizu et al., 2014; Tervo et al., 2016; Zingg et al., 2017; Fig. 6F), its application as an anterograde transsynaptic tool must be limited to established unidirectional pathways. In addition, there is currently no way to initiate AAV1 transsynaptic spread from a genetically specified starter cell population. Resolving these two issues is therefore critical for expanding the application of this technique to reciprocally connected brain regions and refining its specificity as a circuit mapping tool. Future studies may seek to overcome these limitations by designing and exploring novel extracellular receptor and AAV capsid systems (Bedbrook et al., 2018; Sun and Schaffer, 2018; Pillay and Carette, 2017) that enable conditional uptake and transsynaptic transport of AAV in 
genetically specified neurons, but not neighboring cell types or afferent terminals.

\section{References}

Agnati LF, Zoli M, Strömberg I, Fuxe K (1995) Intercellular communication in the brain: wiring versus volume transmission. Neuroscience 69: 711726.

Arroyo S, Bennett C, Hestrin S (2014) Nicotinic modulation of cortical circuits. Front Neural Circuits 8:30.

Aschauer DF, Kreuz S, Rumpel S (2013) Analysis of transduction efficiency, tropism and axonal transport of AAV serotypes 1, 2, 5, 6, 8 and 9 in the mouse brain. PLoS One 8:e76310.

Atkins MJ, Apps R (1997) Somatotopical organisation within the climbing fibre projection to the paramedian lobule and copula pyramidis of the rat cerebellum. J Comp Neurol 389:249-263.

Bedbrook CN, Deverman BE, Gradinaru V (2018) Viral Strategies for Targeting the Central and Peripheral Nervous Systems. Annu Rev Neurosci 41:323-348.

Beier KT, Saunders A, Oldenburg IA, Miyamichi K, Akhtar N, Luo L, Whelan SPJ, Sabatini B, Cepko CL (2011) Anterograde or retrograde transsynaptic labeling of CNS neurons with vesicular stomatitis virus vectors. Proc Natl Acad Sci U S A 108:15414-15419.

Beier KT (2019) Hitchhiking on the neuronal highway: mechanisms of transsynaptic specificity. J Chem Neuroanat 99:9-17.

Beltramo R, Scanziani M (2019) A collicular visual cortex: neocortical space for an ancient midbrain visual structure. Science 363:64-69.

Bennett PJ, Maier E, Brecht M (2019) Involvement of rat posterior prelimbic and cingulate area 2 in vocalization control. Eur J Neurosci 50:31643180.

Brodal P, Bjaalie JG (1992) Organization of the pontine nuclei. Neurosci Res 13:83-118

Castle MJ, Gershenson ZT, Giles AR, Holzbaur ELF, Wolfe JH (2014a) Adeno-associated virus serotypes 1, 8, and 9 share conserved mechanisms for anterograde and retrograde axonal transport. Hum Gene Ther 25:705-720.

Castle MJ, Perlson E, Holzbaur EL, Wolfe JH (2014b) Long-distance axonal transport of AAV9 Is driven by dynein and kinesin-2 and is trafficked in a highly motile Rab7-positive compartment. Mol Ther 22:1-13.

Cembrowski MS, Phillips MG, DiLisio SF, Shields BC, Winnubst J, Chandrashekar J, Bas E, Spruston N (2018) Dissociable Structural and Functional Hippocampal Outputs via Distinct Subiculum Cell Classes. Cell 173:1280-1292.e18

Centanni SW, Morris BD, Luchsinger JR, Bedse G, Fetterly TL, Patel S, Winder DG (2019) Endocannabinoid control of the insular-bed nucleus of the stria terminalis circuit regulates negative affective behavior associated with alcohol abstinence. Neuropsychopharmacology 44:526-537.

Coddington LT, Rudolph S, Vande Lune P, Overstreet-Wadiche L, Wadiche JI (2013) Spillover-mediated feedforward inhibition functionally segregates interneuron activity. Neuron 78:1050-1062.

Deverman BE, Pravdo PL, Simpson BP, Kumar SR, Chan KY, Banerjee A, Gradinaru V (2016) Cre-dependent selection yields AAV variants for widespread gene transfer to the adult brain. Nat Biotechnol 34:204-209.

Dong HW (2007) The Allen Reference Atlas: A Digital Color Brain Atlas Of The C57BL/6J Male Mouse. Hoboken: John Wiley and Sons, Inc.

Do JP, Xu M, Lee SH, Chang WC, Zhang S, Chung S, Dan Y (2016) Cell type-specific long-range connections of basal forebrain circuit. eLife 5: e13214.

Gouwens NW, Sorensen SA, Berg J, Lee C, Jarsky T, Ting J, Sunkin SM, Feng D, Anastassiou CA, Barkan E, Bickley K, Blesie N, Braun T, Brouner K, Budzillo A, Caldejon S, Casper T, Castelli D, Chong P, Crichton K, et al. (2019) Classification of electrophysiological and morphological neuron types in the mouse visual cortex. Nat Neurosci 22:1182-1195.

Gradinaru V, Zhang F, Ramakrishnan C, Mattis J, Prakash R, Diester I, Goshen I, Thompson KR, Deisseroth K (2010) Molecular and cellular approaches for diversifying and extending optogenetics. Cell 141:154165.

Haery L, Deverman BE, Matho KS, Cetin A, Woodard K, Cepko C, Guerin KI, Rego MA, Ersing I, Bachle SM, Kamens J, Fan M (2019) Adeno-associated virus technologies and methods for targeted neuronal manipulation. Front Neuroanat 13:93.
Hessvik NP, Llorente A (2018) Current knowledge on exosome biogenesis and release. Cell Mol Life Sci 75:193-208.

Huang L, Xi Y, Peng Y, Yang Y, Huang X, Fu Y, Ren C (2019) A visual circuit related to habenula underlies the antidepressive effects of light therapy. Neuron 102:128-142.e8.

Huppé-Gourgues F, Jegouic K, Vaucher E (2018) Topographic organization of cholinergic innervation from the basal forebrain to the visual cortex in the rat. Front Neural Circuits 12:19-10.

Hutson TH, Kathe C, Moon LDF (2016) Trans-neuronal transduction of spinal neurons following cortical injection and anterograde axonal transport of a bicistronic AAV1 vector. Gene Ther 23:231-236.

Ibrahim LA, Mesik L, Ji XY, Fang Q, Li HF, Li YT, Zingg B, Zhang LI, Tao HW (2016) Cross-Modality Sharpening of Visual Cortical Processing through Layer-1-Mediated Inhibition and Disinhibition. Neuron 89:1031-1045.

Janas AM, Sapon" K, Janas T, Stowell MH, Janas T (2016) Exosomes and other extracellular vesicles in neural cells and neurodegenerative diseases. Biochim Biophys Acta 1858:1139-1151.

Kanichay RT, Silver RA (2008) Synaptic and cellular properties of the feedforward inhibitory circuit within the input layer of the cerebellar cortex. J Neurosci 28:8955-8967.

Kim Y, Yang GR, Pradhan K, Venkataraju KU, Bota M, García Del Molino LC, Fitzgerald G, Ram K, He M, Levine JM, Mitra P, Huang ZJ, Wang XJ, Osten P (2017) Brain-wide maps reveal stereotyped cell-type-based cortical architecture and subcortical sexual dimorphism. Cell 171:456469.

Kratochwil CF, Maheshwari U, Rijli FM (2017) The long journey of pontine nuclei neurons: from rhombic lip to cortico-ponto-cerebellar circuitry. Front Neural Circuits 11:33

Li R, Zhu M, Li J, Bienkowski MS, Foster NN, Xu H, Dong HW (2019) Precise segmentation of densely interweaving neuron clusters using Gcut. Nat Commun 10:1549.

Liang F, Xiong XR, Zingg B, Ji XY, Zhang LI, Tao HW (2015) Sensory Cortical Control of a Visually Induced Arrest Behavior via Corticotectal Projections. Neuron 86:755-767.

Lin R, Wang R, Yuan J, Feng Q, Zhou Y, Zeng S, Ren M, Jiang S, Ni H, Zhou C, Gong H, Luo M (2018) Cell-type-specific and projection-specific brain-wide reconstruction of single neurons. Nat Methods 15:10331036.

Lo L, Anderson DJ (2011) A cre-dependent, anterograde transsynaptic viral tracer for mapping output pathways of genetically marked neurons. Neuron 72:938-950.

Loeb JE, Cordier WS, Harris ME, Weitzman MD, Hope TJ (1999) Enhanced expression of transgenes from adeno-associated virus vectors with the woodchuck hepatitis virus posttranscriptional regulatory element: implications for gene therapy. Hum Gene Ther 10:2295-2305.

Luo L, Callaway EM, Svoboda K (2018) Genetic dissection of neural circuits: a decade of progress. Neuron 98:256-281.

Mathews PJ, Lee KH, Peng Z, Houser CR, Otis TS (2012) Effects of climbing fiber driven inhibition on purkinje neuron spiking. J Neurosci 32:1798817997.

Masamizu Y, Tanaka YR, Tanaka YH, Hira R, Ohkubo F, Kitamura K, Isomura Y, Okada T, Matsuzaki M (2014) Two distinct layer-specific dynamics of cortical ensembles during learning of a motor task. Nat Neurosci 17:987-994.

McCarty DM (2008) Self-complementary AAV vectors; advances and applications. Mol Ther 16:1648-1656.

Nassi JJ, Cepko CL, Born RT, Beier KT (2015) Neuroanatomy goes viral! Front Neuroanat 9:80.

Nietz AK, Vaden JH, Coddington LT, Overstreet-Wadiche L, Wadiche JI (2017) Non-synaptic signaling from cerebellar climbing fibers modulates Golgi cell activity. ELife 6:1-22.

Odeh F, Ackerley R, Bjaalie J, Apps R (2005) Pontine maps linking somatosensory and cerebellar cortices are in register with climbing fiber somatotopy. J Neurosci 25:5680-5690.

Ogawa SK, Cohen JY, Hwang D, Uchida N, Watabe-Uchida M (2014) Organization of monosynaptic inputs to the serotonin and dopamine neuromodulatory systems. Cell Rep 8:1105-1118.

Palay SL, Chan-Palay V (1974) Cerebellar cortex: cytology and organization. Berlin; Heidelberg: Springer.

Petreanu L, Mao T, Sternson SM, Svoboda K (2009) The subcellular organization of neocortical excitatory connections. Nature 457:1142-1145. 
Pillay S, Carette JE (2017) Host determinants of adeno-associated viral vector entry. Curr Opin Virol 24:124-131.

Polack PO, Friedman J, Golshani P (2013) Cellular mechanisms of brain state-dependent gain modulation in visual cortex. Nat Neurosci 16:13311339.

Prouty EW, Chandler DJ, Waterhouse BD (2017) Neurochemical differences between target-specific populations of rat dorsal raphe projection neurons. Brain Res 1675:28-40.

Raposo G, Stoorvogel W (2013) Extracellular vesicles: exosomes, microvesicles, and friends. J Cell Biol 200:373-383.

Rothermel M, Brunert D, Zabawa C, Diaz-Quesada M, Wachowiak M (2013) Transgene expression in target-defined neuron populations mediated by retrograde infection with adeno-associated viral vectors. J Neurosci 33:15195-15206.

Schaivo G, Benfenati F, Poulain B, Rossetto O, Polverino de Laureto P, DasGupta BR, Montecucco C (1992) Tetanus and botulinum-B neurotoxins block neurotransmitter release by proteolytic cleavage of synaptobrevin. Nature 359:832-835.

Schoch S, Deák F, Königstorfer A, Mozhayeva M, Sara Y, Südhof TC, Kavalali ET (2001) SNARE function analyzed in synaptobrevin/VAMP knockout mice. Science 294:1117-1122.

Schulman JA, Bloom FE (1981) Golgi cells of the cerebellum are inhibited by inferior olive activity. Brain Res 210:350-355.

Schwarz LA, Miyamichi K, Gao XJ, Beier KT, Weissbourd B, DeLoach KE, Ren J, Ibanes S, Malenka RC, Kremer EJ, Luo L (2015) Viral-genetic tracing of the input-output organization of a central noradrenaline circuit. Nature 524:88-92.

Sengupta A, Holmes A (2019) A discrete dorsal raphe to basal amygdala 5-ht circuit calibrates aversive memory. Neuron 103:489-505.e7.

Shambes G, Gibson J, Welker W (1978) Fractured somatotopy in granule cell tactile areas of rat cerebellar hemispheres revealed by micromapping. Brain Behav Evol 15:116-140.

Sousa VH, Miyoshi G, Hjerling-Leffler J, Karayannis T, Fishell G (2009) Characterization of Nkx6-2-derived neocortical interneuron lineages. Cereb Cortex 19:i1-10.

Sun S, Schaffer DV (2018) Engineered viral vectors for functional interrogation, deconvolution, and manipulation of neural circuits. Curr Opin Neurobiol 50:163-170.

Suzuki L, Coulon P, Sabel-Goedknegt EH, Ruigrok TJ (2012) Organization of cerebral projections to identified cerebellar zones in the posterior cerebellum of the rat. J Neurosci 32:10854-10869.

Szapiro G, Barbour B (2007) Multiple climbing fibers signal to molecular layer interneurons exclusively via glutamate spillover. Nat Neurosci 10:735-742.

Tervo DGR, Hwang BY, Viswanathan S, Gaj T, Lavzin M, Ritola KD, Lindo S, Michael S, Kuleshova E, Ojala D, Huang CC, Gerfen CR, Schiller J, Dudman JT, Hantman AW, Looger LL, Schaffer DV, Karpova AY (2016) A designer AAV variant permits efficient retrograde access to projection neurons. Neuron 92:372-382.

Trouche S, Koren V, Doig NM, Ellender TJ, El-Gaby M, Lopes-Dos-Santos V, Reeve HM, Perestenko PV, Garas FN, Magill PJ, Sharott A, Dupret D (2019) A hippocampus-accumbens tripartite neuronal motif guides appetitive memory in space. Cell 176:1393-1406.e16.
Vianna DML, Brandão ML (2003) Anatomical connections of the periaqueductal gray: specific neural substrates for different kinds of fear. Braz J Med Biol Res 36:557-566.

Von Bartheld CS, Altick AL (2011) Multivesicular bodies in neurons: distribution, protein content, and trafficking functions. Prog Neurobiol 93:313-340

Voogd J, Pardoe J, Ruigrok TJH, Apps R (2003) The distribution of climbing and mossy fiber collateral branches from the copula pyramidis and the paramedian lobule: congruence of climbing fiber cortical zones and the pattern of zebrin banding within the rat cerebellum. J Neurosci 23:46454656.

Wang L, Gillis-Smith S, Peng Y, Zhang J, Chen X, Salzman CD, Ryba NJP, Zuker CS (2018) The coding of valence and identity in the mammalian taste system. Nature 558:127-131.

Weissbourd B, Ren J, DeLoach KE, Guenthner CJ, Miyamichi K, Luo L (2014) Presynaptic partners of dorsal raphe serotonergic and GABAergic neurons. Neuron 83:645-662.

Wickersham IR, Lyon DC, Barnard RJ, Mori T, Finke S, Conzelmann K-K, Young JAT, Callaway EM (2007) Monosynaptic Restriction of Transsynaptic Tracing from Single, Genetically Targeted Neurons. Neuron 53:639-647.

Winnubst J, Bas E, Ferreira TA, Wu Z, Economo MN, Edson P, Arthur BJ, Bruns C, Rokicki K, Schauder D, Olbris DJ, Murphy SD, Ackerman DG, Arshadi C, Baldwin P, Blake R, Elsayed A, Hasan M, Ramirez D, Dos Santos B, et al. (2019) Reconstruction of 1,000 projection neurons reveals new cell types and organization of long-range connectivity in the mouse brain. Cell 179:268-281.

Woods NI, Vaaga CE, Chatzi C, Adelson JD, Collie MF, Perederiy JV, Tovar KR, Westbrook GL (2018) Preferential targeting of lateral entorhinal inputs onto newly integrated granule cells. J Neurosci 38:5843-5853.

Xiong XR, Liang F, Zingg B, Ji XY, Ibrahim LA, Tao HW, Zhang LI (2015) Auditory cortex controls sound-driven innate defense behaviour through corticofugal projections to inferior colliculus. Nature Communications 6:7224.

Xu W, Edgley SA (2008) Climbing fibre-dependent changes in Golgi cell responses to peripheral stimulation. J Physiol 586:4951-4959.

Yamamoto M, Wada N, Kitabatake Y, Watanabe D, Anzai M, Yokoyama M, Teranishi Y, Nakanishi S (2003) Reversible suppression of glutamatergic neurotransmission of cerebellar granule cells in vivo by genetically manipulated expression of tetanus neurotoxin light chain. J Neurosci 23:6759-6767.

Yao J, Zhang Q, Liao X, Li Q, Liang S, Li X, Zhang Y, Li X, Wang H, Qin H, Wang M, Li J, Zhang J, He W, Zhang W, Li T, Xu F, Gong H, Jia H, Xu $\mathrm{X}$, Yan J, Chen X (2018) A corticopontine circuit for initiation of urination. Nat Neurosci 21:1541-1550.

Zeng WB, Jiang HF, Gang YD, Song YG, Shen ZZ, Yang H, Dong X, Tian YL, Ni RJ, Liu Y, Tang N, Li X, Jiang X, Gao D, Androulakis M, He XB, Xia HM, Ming YZ, Lu Y, Zhou JN, et al. (2017) Anterograde monosynaptic transneuronal tracers derived from herpes simplex virus 1 strain H129. Mol Neurodegeneration 12:38.

Zingg B, Chou X, Zhang Z, Mesik L, Liang F, Tao HW, Zhang LI (2017) AAV-mediated anterograde transsynaptic tagging: mapping corticocollicular input-defined neural pathways for defense behaviors. Neuron 93:33-47. 